\title{
MiPlato Serie 10 Consejos de Educación en Nutrición ${ }^{1}$
}

\section{USDA Centro para Políticas y Promoción de la Nutrición, con una introducción por Linda B. Bobroff $^{2}$}

Despues de introducir MiPlato en junio de 2011, el Departamento de Agricultura de los EEUU (USDA) desarolló una seria de hojas informativas para ayudar a los consumidores utilizar los consejos dietéticos de los Pautas Dietéticas de 2010. En 2013, el USDA comenzó proveer las hojas de consejos en Español. Estas hojas de consejos se distribuyen por el UF/IFAS para la facultad de Extensión, los profesionales de salud, y los consumidores.

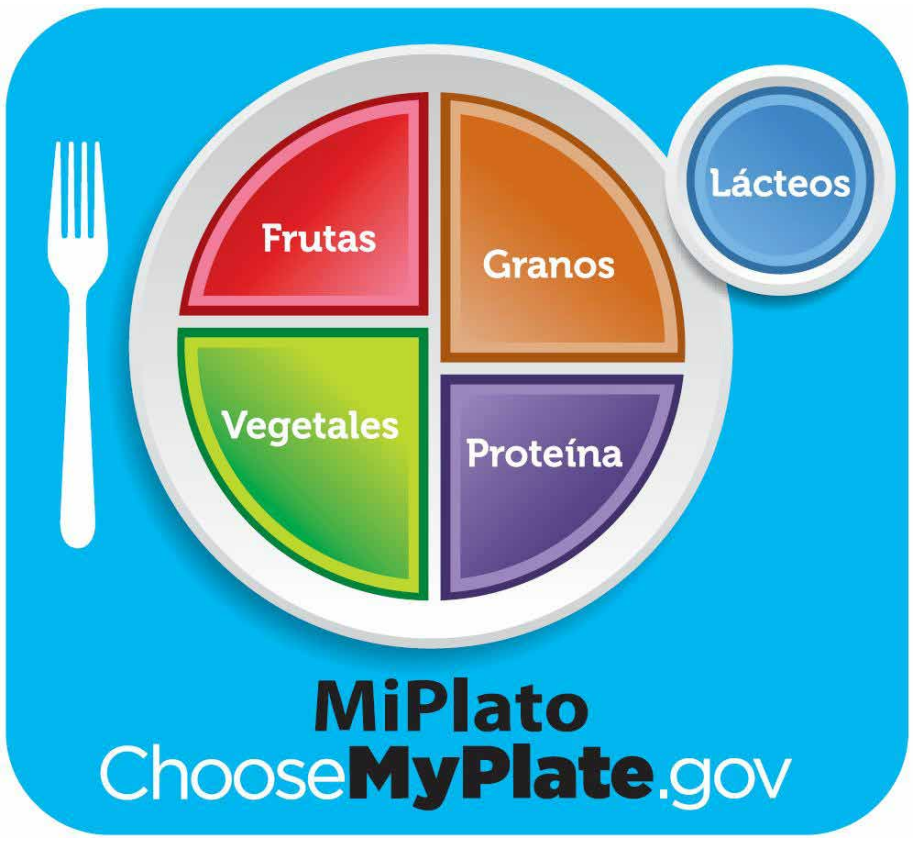

Figure 1. Créditos: http://choosemyplate.gov

\section{Contenidos}

1. Elija MiPlato

2. Agregue más vegetales a sus comidas diarias

3. Enfóquese en las frutas

4. Haga que la mitad de los granos que consume sean integrals

5. ¿Ha consumido lácteos hoy?

6. En lo que concierne a las proteínas, la variedad es la clave

7. Cómo preparer platos sanos

8. La alimentación sana para los vegetarianos

9. La buena compra de vegetales y frutas

10. Avive sus comidas con vegetales y frutas

11. Vegetales y frutas para niños

12. Dé buen ejemplo de salud a los niños

13. Reduzca el consumo de golosinas de sus hijos

14. La sal y el sodio

15. Coma productos marinos dos veces a la semana

16. Coma mejor dentro del presupuesto

17. Use SuperTracker a su manera

18. Disfrute de sus alimentos, pero coma menos

19. Seleccione sus bebidas saludablemente

20. Haz que las celebraciones sean divertidas, saludables y activas

21. El día escolar ahora es más saludable

22. Escoja productos integrales

23. Sanidad en la alimentación

24. Los refrigerios de MiPlato consejos para los padres

25. Alimentación saludable para un estilo de vida activa

26. Sea exigente en el salón comedor

1. This English version of this document is MyPlate Nutrition Education Series (FCS DG10 TS 1-31). Este documento es FCS DG10 TS 1-31SP, uno de una serie del Departamento de Ciencias de la Familia, la Juventud y la Comunidad, UF/IFAS Extensión. Revisado: octubre 2013. Por favor visite el sitio en la web en EDIS http://edis.ifas.ufl.edu.

2. Linda B. Bobroff, PhD, RD, LD/N, profesora, Departamento de Ciencias de la Familia, la Juventud y la Comunidad, UF/IFAS Extensión, Gainesville, FL 32611.

The Institute of Food and Agricultural Sciences (IFAS) is an Equal Opportunity Institution authorized to provide research, educational information and other services only to individuals and institutions that function with non-discrimination with respect to race, creed, color, religion, age, disability, sex, sexual orientation, marital status, national origin, political opinions or affiliations. U.S. Department of Agriculture, Cooperative Extension Service, University of Florida, IFAS, Florida A\&M University Cooperative Extension Program, and Boards of County Commissioners Cooperating. Nick T. Place, Dean 
27. Cambio total en el mini refrigerador

28. Manténgase en forma en la universidad

29. Que su familia se mantenga activa

30. Adultos activos

31. Disfrute comidas de varias culturas

Descargar toda esta serie como una PDF en http://edis.

ifas.ufl.edu/pdffiles/FY/FY139900.pdf (33 pp, 5.93 MB). 


\section{0 \\ consejos \\ elija MiPlato \\ Serie \\ de educación \\ en nutrición \\ 10 consejos para crear un buen plato

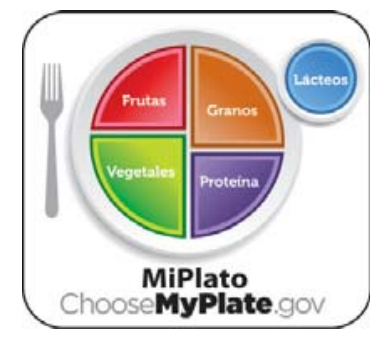

Elegir alimentos para llevar un estilo de vida sano es muy sencillo si sigue estos 10 consejos. Use las ideas de esta lista para balancear las calorías, elegir los alimentos que le conviene comer con mayor frecuencia y reducir la cantidad de alimentos que le conviene comer con menos frecuencia.

\section{1}

\section{balancee las calorías}

El primer paso para controlar su peso es ver

cuántas calorías USTED necesita al día. Vaya a www. ChooseMyPlate.gov para determinar la cantidad de calorías. Hacer actividades físicas también le ayuda a balancear las calorías.

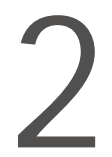

disfrute de sus comidas, pero en cantidades más pequeñas

Tómese el tiempo necesario para disfrutar de sus comidas. El comer demasiado rápido o mientras se concentra en otras cosas puede resultar en que coma demasiadas calorías. Preste atención a las señales del hambre y de saciedad antes, durante y después de las comidas. Úselas para reconocer cuándo debe comer y cuándo ha comido suficiente.

\section{evite las porciones extra grandes}

Use platos, platos hondos y vasos más pequeños. Separe las porciones de alimentos antes de comer. Al salir a comer, elija las opciones de menor tamaño, comparta el platillo o llévese parte de la comida a casa.

\section{4 alimentos que le conviene comer con más frecuencia \\ Coma más vegetales, frutas, granos integrales, y} leche y productos lácteos sin grasa o con $1 \%$ de grasa. Esos alimentos contienen los nutrientes que necesita para la buena salud; entre ellos potasio, calcio, vitamina $D$ y fibra. Haga de ellos la base de sus comidas y bocadillos.

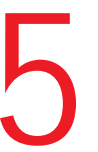
haga que la mitad de su plato consista en frutas y vegetales Al preparar sus comidas, elija vegetales rojos, anaranjados y verduras como tomates, camotes (batatas) y brócoli, así como otros vegetales. Agregue frutas a las comidas como parte de los platos principales o de acompañamiento, o bien como postres.

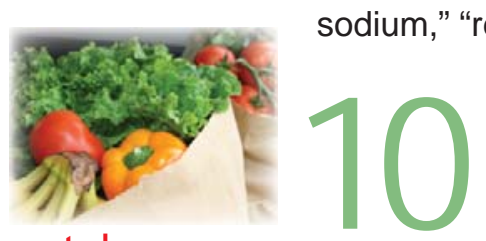

cambie a leche descremada

o baja en grasa (1\%)

Contienen la misma cantidad de calcio y otros nutrientes esenciales que la leche entera, pero sin tantas calorías y grasa saturada.

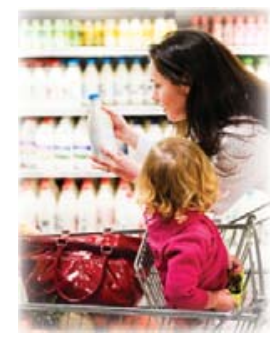

\section{consuma la mitad en granos integrales}

Para consumir más granos integrales, reemplace un producto de grano refinado por un producto de grano integral, como comer pan de trigo integral en lugar de pan blanco o arroz integral en lugar de arroz blanco.

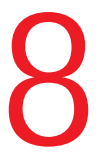

alimentos que le conviene comer con menos frecuencia

Reduzca su consumo de alimentos con grasas sólidas, azúcar y sal adicionales. Estos incluyen pasteles (bizcochos), galletitas, helado, dulces, bebidas endulzadas, pizza y carnes grasas como costillas, chorizo, tocineta y salchichas. Use estos alimentos como antojitos ocasionales, no alimentos para todos los días.

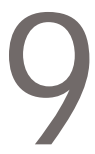

compare el contenido de sodio de los alimentos

Use las etiquetas de Información Nutricional ("Nutrition Facts") para elegir sopas, panes y comidas congeladas con

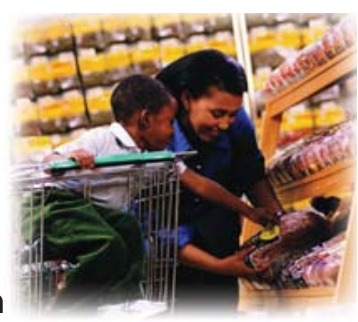
menos sodio. Elija alimentos enlatados marcados "bajo en sodio," "sodio reducido," o "sin sal adicional" ("low in sodium," "reduced sodium," o "without added salt").

azúcar. En las dietas de los estadounidenses, las gaseosas, bebidas de energía y bebidas deportivas representan grandes cantidades adicionales de azúcar y calorías.

\section{beba agua en lugar de bebidas} endulzadas con azúcar

Reduzca las calorías al beber agua o bebidas sin 


\section{0 \\ consejos Serie de educación en nutrición \\ agregue más vegetales a sus comidas diarias 10 consejos para ayudarlo a comer más vegetales

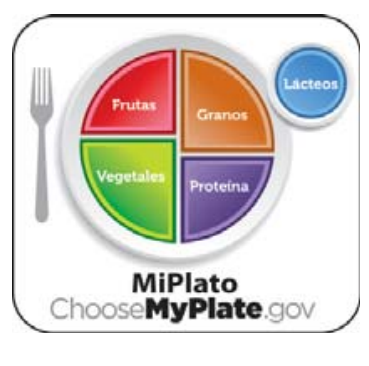

¡Comer más vegetales es fácil! Comer vegetales es importante porque contienen vitaminas y minerales y no contienen muchas calorías. Para incluir más vegetales en sus comidas, siga estos sencillos consejos. Es más fácil de lo que piensa.

\section{]}

descubra maneras de cocinar rápido Cocine vegetales frescos o congelados en el horno de microondas para añadir un plato rápido y fácil a cualquier comida. Coloque pimientos, zanahorias o brócoli en un tazón con poca agua para cocerlos al vapor en el horno de microondas y crear un acompañamiento rápido.

\section{2} prepare ingredientes por adelantado

Pique porciones de pimientos, zanahorias o brócoli. Embólselos para usarlos cuando esté apurado. Puede disfrutarlos en ensaladas, con aderezos

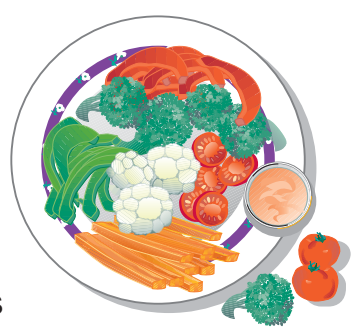
o en tortillas de harina enrolladas con vegetales.

\section{elija vegetales de colores brillantes}

Avive su plato con vegetales color rojo, anaranjado o verde oscuro. Están repletas de vitaminas y minerales. Pruebe calabacín, tomates cereza, camotes o berza. No sólo son ricos en sabor sino muy nutritivos también.

\section{4} busque en el congelador Los vegetales congelados son rápidos y fáciles de usar, y son tan nutritivos como los frescos. Pruebe añadir maíz, guisantes, habichuelas tiernas, espinaca o guisantes dulces congelados a algunos de sus platos favoritos, o bien prepárelos como acompañamientos.

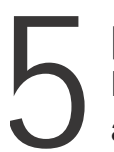

\section{pruebe vegetales enlatados}

Los vegetales enlatados son un buen complemento a cualquier comida, así que tenga a la mano tomates, frijoles rojos, garbanzos, zetas y remolachas enlatadas. Elija latas marcadas "bajo en sodio," "sodio reducido," o "sin sal adicional" ("low in sodium,"

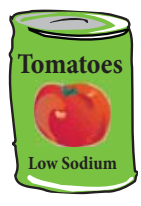

haga que sus ensaladas brillen de color Avive sus ensaladas con vegetales de colores brillantes como frijoles negros, pimientos dulces rojos, rábano rayado, col roja picada o berro. Sus ensaladas no sólo se verán muy bien sinó que también serán deliciosas.

pruebe sopas de vegetales Caliéntelas y cómalas. Pruebe sopas de tomate, calabacín o verduras. Busque sopas con contenido de sodio reducido o bajo.

\section{si sale a comer}

Si sale a cenar, no se preocupe. Al pedir su plato, pida vegetales o ensalada como acompañamiento en lugar de los fritos típicos.

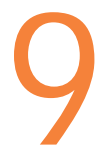
disfrute del sabor de las vegetales de temporada

Para obtener el mejor sabor al más bajo costo, compre vegetales de temporada. Busque las ventas especiales de sus supermercados locales para encontrar las mejores compras de temporada. Visite también el mercado de su comunidad (farmers markets).
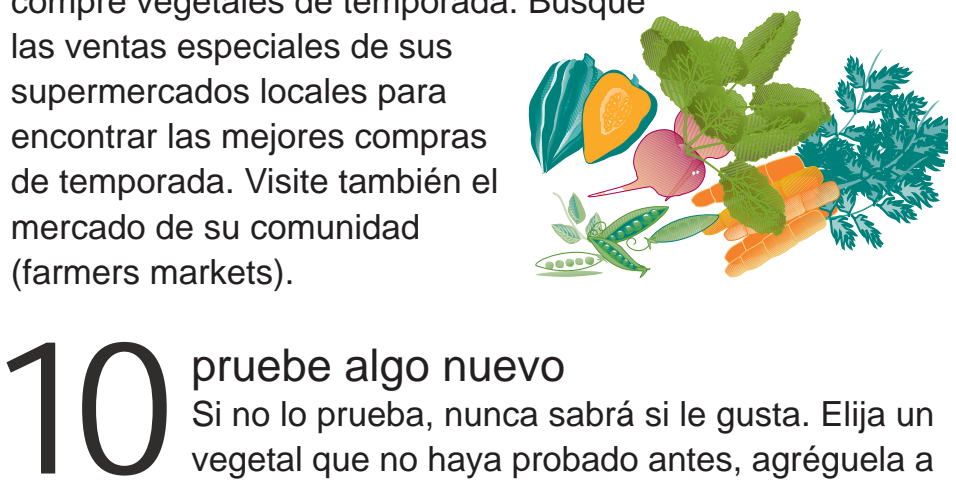
pruebe algo nuevo Si no lo prueba, nunca sabrá si le gusta. Elija un vegetal que no haya probado antes, agréguela a una receta o busque en internet para ver cómo prepararla.

"reduced sodium," or "without added salt"). 


\section{0 \\ consejos Serie \\ de educación en nutrición \\ enfóquese \\ en las frutas}

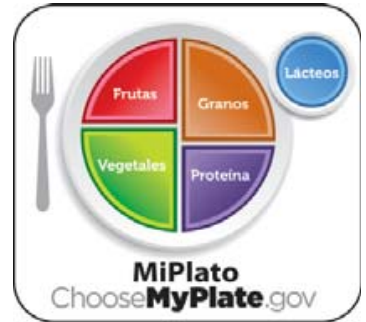

\section{0 consejos para ayudarlo a comer más frutas}

El consumo de frutas brinda beneficios de salud. Las personas que comen más frutas y vegetales como parte de una dieta saludable integral tienen menos riesgos de presentar algunas enfermedades crónicas. Las frutas proveen nutrientes importantes para la salud, como el potasio, la fibra, la vitamina C y el ácido fólico. La mayoría de las frutas son naturalmente bajas en grasa, sodio y calorías. Ninguna de ellas contiene colesterol. Todas las frutas o los jugos de fruta $100 \%$ naturales forman parte del grupo de frutas. Las frutas pueden ser frescas, enlatadas, congeladas o secas, y pueden consumirse enteras, cortadas o en puré.

] manténgalas a la vista Tenga un tazón de frutas enteras sobre la mesa, el mostrador de la cocina o en el refrigerador.

piense en el sabor

Compre frutas frescas de temporada cuando sean menos costosas y estén maduras. Agregue frutas para endulzar una receta.

piense en la variedad

Compre frutas secas, congeladas o enlatadas (en agua o $100 \%$ jugo),

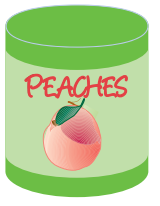
así como frutas frescas para tener siempre cantidades disponibles a mano.

\section{no olvide la fibra}

Elija principalmente frutas enteras o cortadas en lugar de jugos, por los beneficios que la fibra le ofrece.

\section{dé el buen ejemplo}

Dé buen ejemplo a los niños al

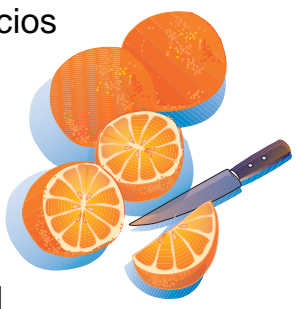
consumir frutas todos los días con las comidas o como bocadillos.

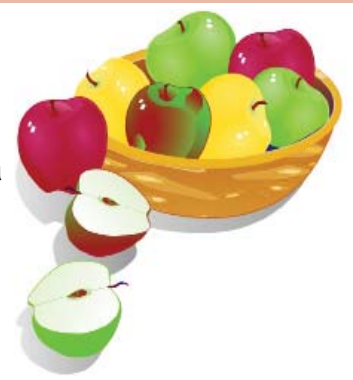

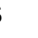




\section{0 \\ consejos \\ Serie \\ de educación \\ haga que la mitad de los granos que consume sean integrales \\ 10 consejos para ayudarlo a consumir granos integrales

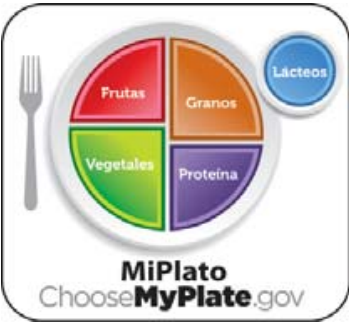

Los alimentos hechos con trigo, arroz, avena, maíz, cebada o cualquier otro grano de cereal son productos de granos. El pan, los fideos y tallarines, la avena, los cereales para el desayuno, las tortillas de harina y la sémola son ejemplos de estos productos. Los granos se dividen en 2 subgrupos: granos integrales y granos refinados. Los granos integrales contienen el grano completo; es decir, la cáscara, el germen y el saco embrional. Las personas que consumen granos integrales como parte de una dieta saludable tienen menos riesgo de presentar algunas enfermedades crónicas.

\section{haga cambios sencillos}

Para que la mitad de los granos que consume sean integrales, sustituya un producto de granos refinados con uno de granos integrales. Por ejemplo, coma pan o roscas de pan de $100 \%$ trigo en lugar de pan o roscas de pan blanco, o bien coma arroz integral en lugar de arroz blanco.

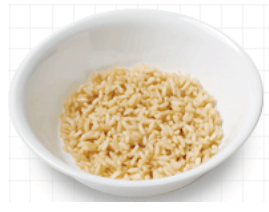

\section{los granos integrales son bocadillos sanos}

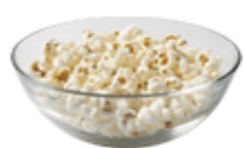
Las palomitas de maíz son hechas de granos integrales y por lo tanto son bocadillos sanos. Prepárelas sin o con poca sal o mantequilla.

Pruebe también galletas $100 \%$ de trigo integral o centeno.

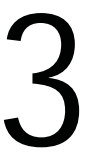
ahorre tiempo

Cocine cantidades adicionales de trigo burgol o cebada cuando tenga tiempo. Congele la mitad para calentar y servir más adelante como complemento rápido.

\section{mézclelo con granos integrales}

Use granos integrales en platos mixtos, como la cebada en sopas o guisados de vegetales y el trigo burgol en platos salteados o cazuelas. Pruebe ensaladas 0 plantos de quinua.

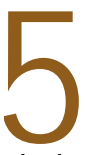
pruebe versiones de trigo integral Para variar, pruebe el arroz integral o fideos y tallarines de trigo integral. Pruebe tomates o pimientos verdes horneados rellenos de arroz integral y macarrones de trigo integral en platos de macarrones con queso.

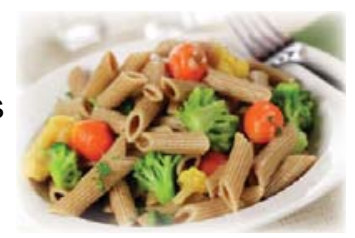

\section{hornee antojitos con granos integrales}

Experimente y reemplace con trigo sarraceno, mijo o harina de avena hasta la mitad del contenido de harina de los panqueques, waffles, molletes y otras recetas con contenido de harina. Tal vez necesite un poco más de levadura para que leuden.

\section{de buen ejemplo a los niños \\ De buen ejemplo a los niños al servir y consumir granos integrales todos los días con las comidas o como bocadillos.}

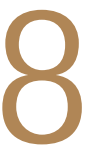

\section{verifique el contenido de fibra}

Use la etiqueta de datos de nutrición para verificar el contenido de fibra de los productos de granos integrales. Las buenas fuentes defibra contienen $10 \%$ a $19 \%$ del valor diario. Las fuentes excelentes contienen un $20 \%$ o más.

\section{sepa qué buscar en las listas de ingredientes \\ Lea las listas de ingredientes}

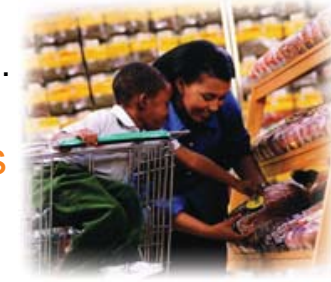

y elija productos que incluyan granos integrales como el primer ingrediente de la lista. Busque "trigo integral," "arroz integral," "burgol," "alforfón," "avena," "harina de maíz integral," "avena de grano integral," "centeno integral," o "arroz silvestre" (busque "whole grain").

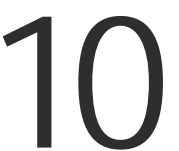
sea un comprador instruido El color de un alimento no indica que se trate de un alimento de granos integrales. Por lo general, los alimentos con etiquetas que dicen "multigrano", "molido a piedra", "100\% trigo", "trigo partido", "siete granos" o "salvado" no son productos $100 \%$ de granos integrales, y es posible que no contengan ningún grano integral. 


\section{0 \\ consejos Serie de educación en nutrición ¿ha consumido lácteos hoy? 10 consejos para ayudarle a comer y beber más productos lácteos descremados o bajos en grasa

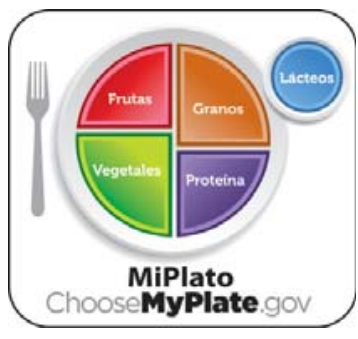

El grupo de lácteos incluye leche, yogur, queso y leche de soja enriquecida. Estos suministran calcio, vitamina D, potasio, proteína y otros nutrientes necesarios para la buena salud durante toda la vida. Elija productos con bajo contenido de grasa o descremados para reducir las calorías y las grasas saturadas. ¿Cuánto se necesita? Los niños más grandes, adolescentes y adultos necesitan 3 tazas* al día, mientras que los niños de 4 a 8 años de edad necesitan 21/2 tazas y los de 2 a 3 años de edad necesitan 2 tazas.

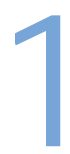
elimine la grasa

Beba leche descremada o baja en grasa (1\%). Si bebe leche entera actualmente, cambie gradualmente a una versión con menos contenido de grasa. El cambio reduce las calorías pero no el contenido de calcio y otros nutrientes esenciales.

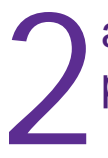
aumente el potasio y la vitamina $D$, pero reduzca el sodio

Elija leche o yogur descremados o con bajo contenido de grasa más frecuentemente que queso. La leche y el yogur tienen más potasio y menos sodio que la mayoría de los quesos. Además, casi todas las variedades de

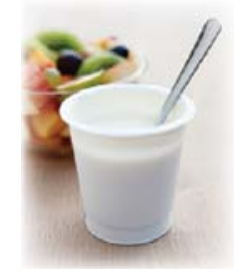
leche y muchos tipos de yogur vienen enriquecidos con vitamina D.

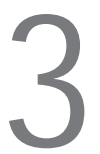

\section{agréguelos a sus comidas}

Use leche o yogur descremado o con contenido bajo de grasa con el cereal y la avena. Agregue yogur con bajo contenido de grasa a las ensaladas de fruta y papas horneadas en lugar de aderezos más grasosos como la crema agria.

\section{Elija quesos con menos grasa}

Muchos quesos tienen un alto contenido de grasas

saturadas. Busque etiquetas que digan "grasa

reducida" o "bajo en grasa" ("reduced fat" o "low fat"). Pruebe marcas o tipos distintos para encontrar los que más le gusten.

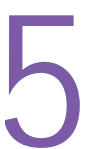

¿y qué del queso crema?

El queso crema regular, la crema y la mantequilla no son parte del grupo de productos lácteos. Son altos en grasas saturadas y carecen o tienen muy poco calcio.

* ¿Qué se considera una taza en el grupo de lácteos? 1 taza de leche o yogur, 11/2 onzas de queso natural, 2 onzas de queso procesado.
6 cambio de ingredientes Use yogur sin sabor cuando una receta de aderezo pida crema agria. Use leche evaporada descremada en lugar de crema y pruebe queso ricotta en lugar de queso crema.

\section{tenga cuidado al elegir productos lácteos dulces \\ Las leches con sabor, los yogures de frutas, yogures} congelados y pudines pueden contener grandes cantidades adicionales de azúcar. Esos azúcares adicionales son calorías sin valor nutritivo. Usted necesita los nutrientes de los productos lácteos, no esas calorías.

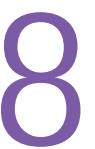
¿bebe café?

De ser así, obtenga su calcio junto con su dosis de cafeína por la mañana. Prepare o pida el café con leche o el capuccino con leche descremada o baja en grasa.

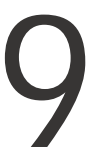
¿no puede beber leche?

Si no tolera la lactosa, pruebe leche sin lactosa o beba la leche en cantidades pequeñas a la vez, o bien pruebe la leche de soja (bebida de soja). Consulte la etiqueta de datos de nutrición para asegurarse de que su leche de soja tenga aproximadamente $300 \mathrm{mg}$ de calcio. El calcio presente en algunos vegetales verdes se absorbe bien pero no será suficiente comer varias tazas al día para satisfacer las necesidades de calcio.

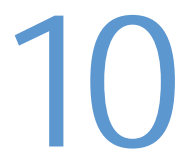

\section{cuídese y cuide a su familia} Los padres que beben leche y comen productos lácteos les muestran a sus hijos que eso es importante. Los productos lácteos son de importancia especial para los huesos en desarrollo de los niños y los adolescentes. Incluya regularmente alimentos lácteos descremados o bajos en grasa en las comidas y los bocadillos para que todos se beneficien. 


\section{0 \\ consejos Serie de educación en nutrición}

\section{en lo que concierne a las proteínas, la variedad es la clave 10 consejos para elegir proteínas

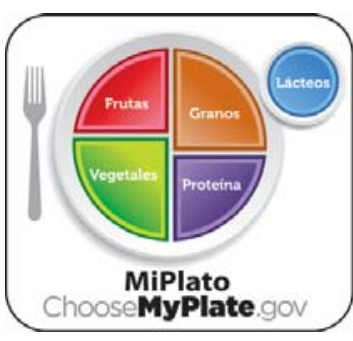

\section{La proteína de los alimentos provienen de fuentes tanto animales (carne, aves, mariscos y huevos) como de plantas (frijoles, guisantes, productos de soja, nueces y semillas). Todos necesitamos proteína; pero la mayoría de los estadounidenses comen cantidades suficientes, y algunos de ellos más de lo que necesitan. ¿Cuánto es suficiente? La mayoría de las personas de 9 años de edad y mayores deben comer de 5 a 7 onzas* de comidas con proteína cada día.}

\section{]}

varíe sus fuentes de proteína

Consuma variedad de alimentos del grupo de proteínas por semana. Pruebe platos preparados con legumbres, nueces, soja, pescados y mariscos.

\section{coma pescados y mariscos dos veces por semana \\ Coma pescado o mariscos en lugar de} carne de res o aves dos veces por semana. Elija pescados y mariscos variados. Incluya opciones más ricas en aceite y más bajas en mercurio, como salmón, trucha y arenque.

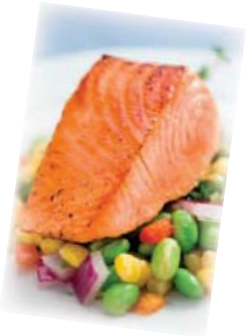

\section{elija carnes de res y aves magras o con}

\section{bajo contenido de grasa}

Elija cortes de carne con bajo contenido de grasa, como paleta y lomo, y carne molida por lo menos $90 \%$ magra. Recorte o escurra la grasa de las carnes y quíteles el pellejo a las carnes de ave.

\section{4} coma huevos

En promedio, comer un huevo al día no aumenta el riesgo de enfermedad cardíaca, así que incluya huevos en sus opciones para la semana. Sólo la yema de huevo contiene colesterol y grasas saturadas, de manera que puede comer tanta clara de huevo como desee.

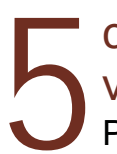
coma proteínas de fuentes vegetales con más frecuencia Pruebe legumbres(frijoles rojos, rosados, negros o blancos, arvejas, garbanzos, puré de garbanzos), productos de soja (tofú, tempeh, hamburguesas vegetarianas), nueces y semillas. Son naturalmente bajas en grasas saturadas y tienen alto contenido de fibra.

* ¿Qué cuenta como una onza de proteína? 1 onza de carne de res 0 ave magra, pescado o mariscos; 1 huevo; 1/4 taza de frijoles o guisantes cocidos; $1 / 2$ onza de nueces o semillas o 1 cucharada de mantequilla de cacahuate (maní).
Distribuido por UF/IFAS Extensión

Visite www.ChooseMyPlate.gov para obtener más información.

\section{nueces y semillas}

Elija nueces o semillas sin sal como bocadillos y agréguelas a las ensaladas o a platos principales en lugar de carne de res o aves. Las nueces y semillas son fuentes concentradas de calorías, de manera que coma porciones más pequeñas para mantener las calorías bajo control.

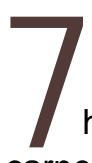
hágalas sabrosas y sanas

Pruebe carnes a la plancha, parrilla, rostizadas $u$ horneadas; estos métodos no agregan grasa. Algunas carnes magras necesitan ser cocidas lentamente y con líquido para que queden tiernas. Evite empanar las carnes de res o aves, ya que eso agrega calorías.

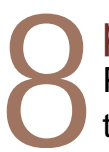
prepárese un sándwich saludable Prepare sándwiches de pavo, rosbif, tuna o salmón enlatados, o bien mantequilla de cacahuate (maní). Muchos embutidos, como la salchicha ahumada regular o el salame, tienen alto contenido de grasa y sodio. Cómalas como antojitos ocasionales únicamente.

\section{piense en menos al comer porciones} de carne

Saboree el gusto que desee, pero en cantidades más pequeñas. Prepare o pida una hamburguesa más pequeña o filetes tipo "miñón."

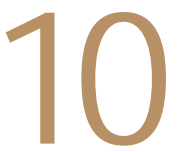

\section{verifique el contenido de sodio}

Verifique la etiqueta de datos de nutrición para limitar el sodio. A muchas comidas enlatadas, entre ellas los frijoles y las carnes, se les agrega sal. Muchas carnes procesadas, como el jamón, las salchichas y los fiambres o embutidos, tienen alto contenido de sodio. Algunos cortes de pollo, pavo y cerdo se marinan en soluciones de sal para agregarles sabor y terneza. 


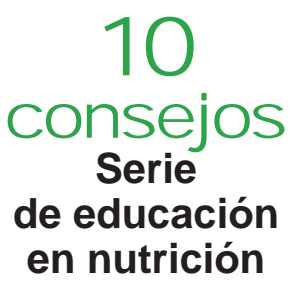

\section{cómo preparar platos sanos}

10 consejos para platos sanos

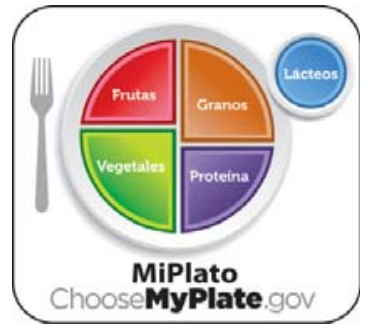

Un plato sano comienza con más vegetales y frutas, y porciones más pequeñas de proteínas y granos. Piense en cómo ajustar las porciones en su plato para obtener más de lo que necesita sin demasiadas calorías. Tampoco olvide los productos lácteos; haga de ellos su bebida de acompañamiento o agregue a su plato productos lácteos descremados o con bajo contenido de grasa.

\section{haga que la mitad de su plato consista en frutas y vegetales}

Las vegetales y las frutas están repletas de nutrientes que tal vez le ayuden a promover la buena salud. Elija vegetales de color rojo, anaranjado y verde oscuro como tomates, camotes (batatas) y brócoli.

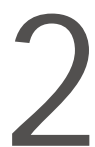
agregue proteínas magras Elija alimentos ricos en proteína, como carne de res y cerdo magras, pollo y pavo, frijoles o tofú. Dos veces por semana, haga que la proteína en su plato provenga de pescados y mariscos.

\section{3} incluya granos integrales Intente que por lo menos la mitad de los granos consumidos sean granos integrales. Busque las designaciones "100\% granos integrales" o "100\% trigo integral" ("whole grain, whole wheat") en las etiquetas. Los granos integrales contienen más nutrientes, como fibra, que los granos refinados.

\section{4} no olvide los productos lácteos Acompañe sus comidas con una taza de leche descremada o baja en grasa. Esta contiene la misma cantidad de calcio y otros nutrientes esenciales que la leche entera, pero con menos grasa y calorías. ¿No bebe leche? Pruebe leche de soja (bebida de soja) como su bebida, o bien incluya en su comida yogur descremado con bajo contenido de grasa.

\section{evite la grasa adicional}

El uso de salsas o aderezos espesos agregará grasas y calorías a comidas que de otro modo serían sanas. Por ejemplo, el brócoli al vapor es excelente, pero evite cubrirlo con salsa de queso. Pruebe otras opciones, como queso parmesano rallado bajo en grasa o jugo de limón.

\section{coma con calma}

Saboree la comida. Coma despacio, disfrute del sabor y las texturas, y preste atención a cómo se siente. Tenga en cuenta que comer demasiado rápido puede resultar en comer demasiado.

\section{use un plato más pequeño}

Use platos más pequeños a la hora de comida para controlar las porciones. De esa manera puede "limpiar el plato" y sentirse satisfecho sin comer demasiado.

\section{controle sus alimentos}

Coma en casa con más frecuencia para que sepa exactamente lo que come. Si sale a comer, estudie y compare la información de nutrición. Elija opciones más sanas como alimentos horneados en lugar de fritos.

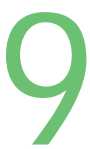

\section{pruebe alimentos nuevos}

Mantenga el interés al elegir alimentos

nuevos que tal vez nunca antes ha probado, como mangos, lentejas o lechuga japonesa. ¡Tal vez encuentre su nuevo alimento favorito! Intercambie recetas sabrosas y divertidas con sus amigos, o busque recetas nuevas en línea.

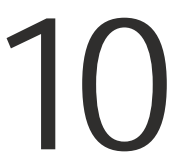

\section{satisfaga el gusto dulce de} manera sana

Permítase un postre naturalmente dulce: jfrutas! Sirva ensalada de frutas frescas o un postre helado con yogur y fruta. Para un postre caliente, hornee manzanas y cúbralas con canela. 


\section{0 \\ consejos Serie de educación en nutrición}

\section{La alimentación sana para los vegetarianos 10 consejos para vegetarianos}

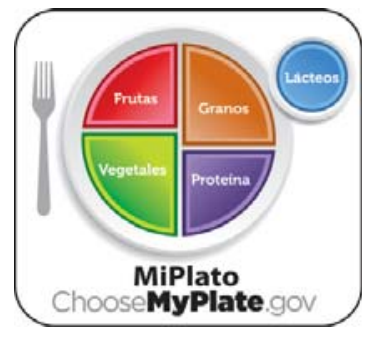

Una dieta vegetariana puede ser una opción sana. La clave está en consumir alimentos variados y la cantidad correcta de alimentos para satisfacer sus necesidades de calorías y nutrientes.

$\square$ piense en las proteínas

Las necesidades de proteínas pueden satisfacerse fácilmente al consumir varios alimentos de origen vegetal. Las fuentes de proteínas para los vegetarianos incluyen las legumbres, las nueces y los productos de soja (tofú, tempeh). Los lacto-ovo-vegetarianos que consumen productos lácteos y huevos también obtienen proteínas de los huevos y productos lácteos.

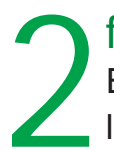
fortalézcase con fuentes de calcio El calcio se utiliza en la formación de los huesos y los dientes. Algunos vegetarianos consumen productos lácteos, los cuales son excelentes fuentes de calcio. Otras fuentes de calcio para los vegetarianos incluyen la leche de soja enriquecida con calcio (bebida de soja), el tofu hecho con sulfato de calcio, los cereales para el desayuno y el jugo de naranja fortalecidos

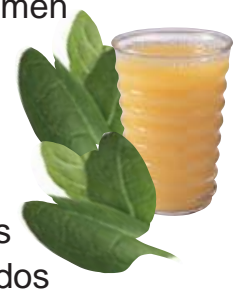
con calcio y algunos vegetales de hoja verde oscuro (berzas, nabo, hojas de mostaza y bok choy).

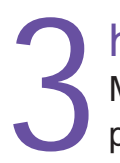

\section{haga cambios sencillos}

Muchos platos principales populares son o pueden prepararse vegetarianos, como pasta primavera con salsa marinara o pesto, pizza vegetariana, salteado de tofu y vegetales, y burritos rellenos de frijoles.

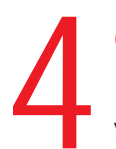
cocine al aire libre

En las barbacoas, pruebe las hamburguesas vegetarianas o de soja, salchichas de soja, tofu o tempeh marinados y brochetas de fruta. ¡Los vegetales a la parrilla también son sabrosos!

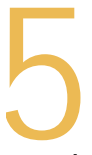

\section{incluya frijoles y guisantes}

Por su alto contenido nutricional, se recomienda el consumo de frijoles

y guisantes a todas las personas, tanto vegetarianas como no vegetarianas.

Disfrute de chili vegetariano, ensalada de mezcla de tres frijoles, o sopa de arvejas. Prepare un sándwich en pan pita relleno de puré de garbanzos ("hummus").

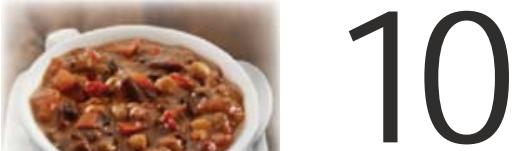

encuentre una dieta vegetariana que funcione para usted

Vaya a www.dietaryguidelines.gov y consulte los apéndices 8 y 9 de la edición de 2010 de las Guías Alimenticias para los Estadounidenses del USDA para ver adaptaciones vegetarianas de los patrones de alimentación para 12 niveles de calorías. 


\section{0 \\ consejos \\ Serie \\ de educación \\ la buena compra \\ en nutrición de vegetales y frutas}

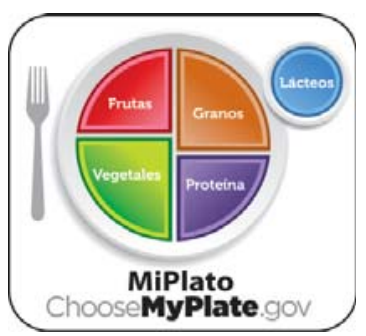

\section{0 consejos para economizar en vegetales y frutas}

Es posible incluir vegetales y frutas en todo presupuesto. Tomar decisiones nutritivas no tiene que costar demasiado dinero. Comer estos alimentos en cantidades suficientes promueve la buena salud y puede ayudarle a reducir el riesgo de contraer ciertas enfermedades. Hay muchas maneras económicas de satisfacer sus necesidades de consumo de frutas y vegetales.

] celebre la temporada

Use frutas y vegetales frescos de temporada. Son

fáciles de obtener, saben mejor y, por lo general, cuestan menos. Su mercado local es una fuente excelente de productos frescos de temporada.

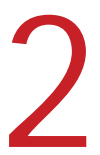
no vale la pena pagar el precio completo

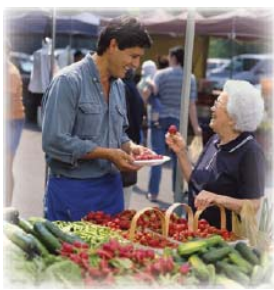

Busque en el periódico local, en internet y en las tiendas las ventas especiales, cupones de descuento y ofertas que pueden reducir el costo de los alimentos. A menudo, puede comprar más por menos en supermercados (o tiendas de descuento, si están disponibles).

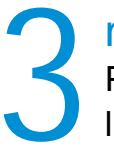

mantenga una lista de compras

Planifique sus comidas por adelantado y haga una lista de compras. Ahorrará dinero al comprar sólo lo que necesita. No vaya de compras cuando tenga hambre. Ir de compras después de comer hará que sea más fácil pasar por alto los bocadillos tentadores. Tendrá más dinero disponible en su presupuesto para comprar vegetales y frutas.

\section{4} pruebe productos enlatados o congelados

Compare el precio y la cantidad de raciones de las variedades frescas, enlatadas y congeladas de los mismos vegetales o frutas.

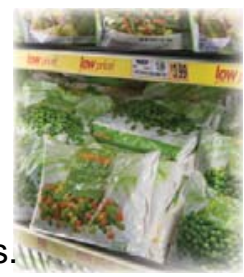
Los artículos enlatados y congelados pueden ser menos costosos que los frescos. En el caso de artículos enlatados, elija frutas envasadas en $100 \%$ jugo de fruta y vegetales con etiquetas que indican "bajo en sodio" o "sin sal adicional" ("low in sodium" o "without added salt").

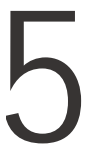
compre cantidades pequeñas frecuentemente

Algunos vegetales y frutas frescas no duran mucho. Compre cantidades pequeñas con mayor frecuencia para garantizar que pueda comerlos y no se echen a perder.

\section{compre a granel cuando los artículos} estén en venta especial

En el caso de los vegetales y las frutas que usa con frecuencia, las bolsas más grandes son más económicas. Las frutas y vegetales enlatados y congelados duran más y se pueden comprar en cantidades grandes cuando están en venta especial.

\section{las marcas de las tiendas = ahorros para usted Si es posible elija comprar las marcas de las tiendas. Obtendrá un producto idéntico o similar a un precio} módico. Si su supermercado tiene una tarjeta de descuento para miembros, inscríbase para ahorrar aún más.

mantenga las cosas simples Compre los vegetales y las frutas en sus formas más simples. Los alimentos pre cortados, pre lavados, listos para el consumo y procesados son convenientes pero a menudo cuestan mucho más que si se compran en sus formas frescas.

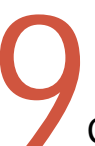

cultive sus propios vegetales y frutas

Cultive alimentos frescos, económicos y sabrosos, en el huerto, jardín, o en el balcón, para añadir a sus comidas. Para los principiantes, las hierbas, los pepinos,

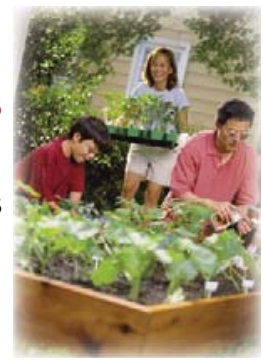
pimientos o tomates son buenas opciones. Busque en su biblioteca local o en línea para obtener más información sobre cómo sembrar un huerto.

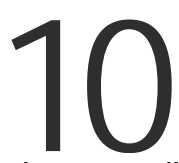
planifique y cocine de manera astuta Prepare de antemano y congele sopas, guisos u otros platos con vegetales. Eso le ahorrará tiempo y dinero. Agregue restos de vegetales a cazuelas, o mézclelos para hacer sopa. Las frutas maduras son excelentes para hacer batidos o para hornear. 


\section{0 \\ consejos Serie \\ de educación en nutrición}

\section{Avive sus comidas con vegetales y frutas \\ 10 consejos para mejorar sus comidas con vegetales y frutas

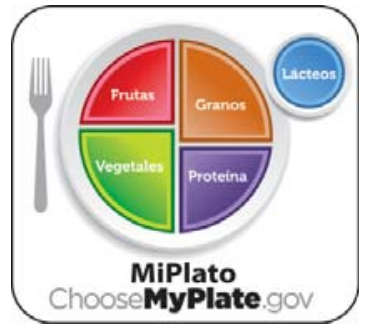

Descubra los muchos beneficios de agregar vegetales y frutas a sus comidas. Son bajos en contenido de grasas y calorías, también son buenas fuentes de fibra y otros nutrientes. A la mayoría de los estadounidenses les conviene comer más de 3 tazas y a algunos hasta 6 tazas de vegetales y frutas todos los días. Los vegetales y las frutas no sólo agregan valor nutritivo a las comidas; también les agregan color, sabor y textura. Explore las siguientes maneras de llevar alimentos sanos a la mesa.

\section{]}

\section{encienda la parrilla}

Use la parrilla para cocer vegetales y frutas. Pruebe brochetas de setas o champiñones, zanahorias, pimientos o papas a la parrilla. Únteles aceite para que no se resequen. Las frutas a la parrilla, como melocotones, piña o mangos, agregan mucho sabor a las parrilladas.

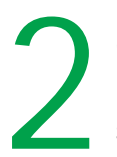
amplíe el sabor de sus cazuelas Mezcle vegetales como cebollas salteadas, guisantes, frijoles pintos o tomates en su plato favorito para agregarle sabor.

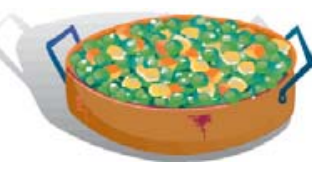

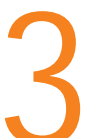
¿tiene planeada una comida italiana? Agregue cantidades adicionales de vegetales a sus platos de fideos o tallarines. Agregue pimientos, espinaca, frijoles rojos, cebolla o tomates cereza a su salsa de tomate tradicional. Los vegetales agregan textura y cuerpo que satisfacen y son bajos en calorías.

\section{sea creativo con sus ensaladas}

Mezcle zanahorias ralladas, fresas, espinaca, berro, trozos de naranja o guisantes para crear una ensalada sabrosa y colorida.

\section{5} La sección de alimentos preparados no sólo tiene ensaladas de vegetales

Al salir a cenar, pruebe comer frutas picadas como postre. Eso le ayudará a evitar los postres horneados con alto contenido de calorías.

\section{diviértase salteando los vegetales}

¡Pruebe algo nuevo! Saltee los vegetales, como brocoli, zanahorias, guisantes dulces, setas o champiñones, o habichuelas tiernas, para agregarlas fácilmente a cualquier comida.

\section{agréguelas a sus sándwiches \\ Ya se trate de un sándwich o una tortilla de harina enrollada, los vegetales van muy bien con ambos. Pruebe rebanadas de tomate, lechuga romana o aguacate en su sándwich o tortilla de harina enrollada de todos los días para agregar sabor.}

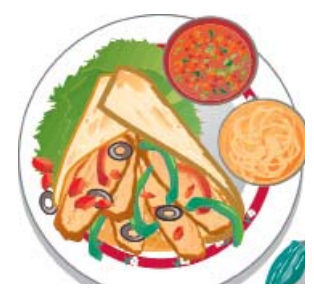

\section{sea creativo con los productos horneados} Para un gusto adicional, agregue manzanas, plátanos, bayas o peras a su receta de mollete o kekito favorito.

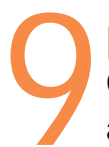

prepare un rico batido de fruta Como postre, mezcle fresas, arándanos o frambuesas con plátano congelado y $100 \%$ jugo de fruta para preparar un delicioso batido de frutas.
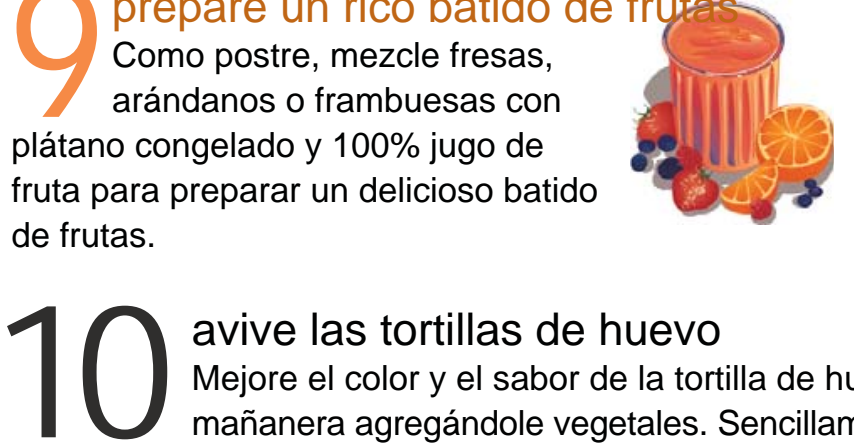

avive las tortillas de huevo

Mejore el color y el sabor de la tortilla de huevo mañanera agregándole vegetales. Sencillamente córtelos, saltéelos y agréguelos a los huevos mientras los coce. Pruebe combinaciones distintas de vegetales, como setas o champiñones, espinaca, cebolla o pimientos dulces. 


\section{0 \\ consejos \\ Serie \\ de educación \\ en nutrición \\ vegetales y frutas para niños}

\section{0 consejos para que los alimentos \\ sanos sean más divertidos para los niños}

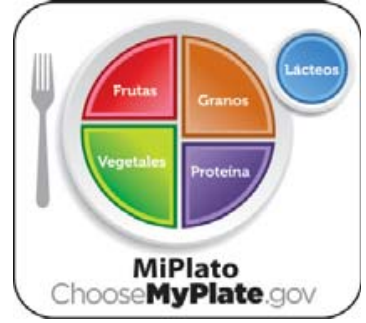

Para animar a los niños a comer vegetales y frutas, hágalas divertidas. Provea ingredientes sanos y permita que los niños ayuden en su preparación según sus edades y destrezas. Los niños tal vez deseen probar comidas que en el pasado han rechazado si ayudaron a prepararlas.

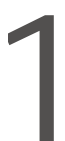
creaciones de batidos

Mezcle yogur o leche descremados o bajos en grasa con trozos de fruta y hielo triturado. Use frutas frescas, congeladas, enlatadas o maduras. Pruebe plátanos, arándanos, melocotones y piña. ¡Si congela las frutas de antemano, no es necesario añadir hielo!

\section{aderezos deliciosos}

A los niños les gusta sumergir alimentos en aderezos.

Prepare un aderezo rápido para los vegetales a base de yogur y condimentos como hierbas o ajo. Sírvalo con vegetales crudos como brócoli, zanahorias o coliflor. Los trozos de fruta combinan muy bien con un aderezo de yogur y canela o vainilla.

\section{3} "orugas" comestibles

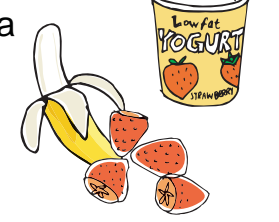
Prepare brochetas con trozos de melón, manzana, naranja y pera. Para la versión con vegetales, use productos como pepinos, calabacín, pimientos o tomates.

\section{4} pizzas personalizadas

Convierta su cocina en una pizzería. Use panecillos ingleses de trigo integral, roscas de pan o pan pita como base. Agregue salsa de tomate, queso bajo en grasa y vegetales o frutas en trozos. Permita que los niños elijan sus favoritos. Luego, ponga las pizzas en el horno para calentarlas.

\section{"mariposas" de mantequilla de cacahuate (maní) con fruta \\ Comience con palillos de zanahoria o apio para el} cuerpo. Use mantequilla de maní para adherir alas, hechas de rebanadas finas de manzana y decórelas con uvas o frutas secas.
6

\section{frutas congeladas}

Los bocadillos congelados seguramente serán muy populares durante los meses cálidos del verano.

Sencillamente coloque frutas frescas, como trozos de melón, en el congelador (enjuáguelos primero). Haga "paletas" congelando bananas sin cáscara con palillos.

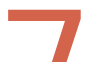
"insectos sobre un tronco"

Use palillos de apio, pepino o zanahoria como troncos y únteles con mantequilla de cacahuate (maní). Ponga frutas secas como pasas, arándanos o cerezas sobre el tronco, dependiendo de qué insecto desee.

\section{Mezcla de nueces y frutas} secas hecha en casa

Prepárela usted mismo. Use las nueces y frutas secas que prefiera, como cacahuate (maní) sin sal, castañas, nueces o semillas de girasol y mézclelas con trozos de manzana, piña, cerezas, albaricoques o pasas secas. Agregue cereal de granos integrales también.

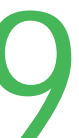

\section{"cara de papa"}

Decore media papa horneada. Coloque rebanadas de tomates cereza, guisantes y queso bajo en grasa sobre la papa para crear una cara cómica.

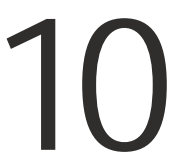
deje que los niños estén a cargo Pídales a sus hijos que nombren las nuevas creaciones de vegetales o frutas. Permítales arreglar las vegetales o frutas crudas para crear formas 0 diseños divertidos.

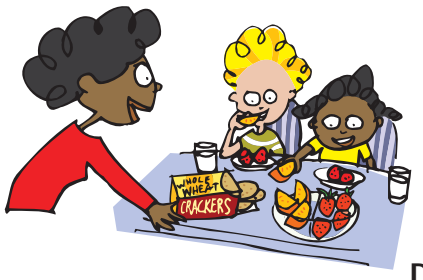

EL USDA es un proveedor y empleador que ofrece igualdad de oportunidades para todos. 


\section{0 \\ consejos \\ Serie \\ de educación \\ en nutrición}

\section{dé buen ejemplo \\ de salud a los niños}

\section{0 consejos para dar buenos ejemplos}

Usted es la influencia más importante para sus hijos. Puede hacer muchas cosas para ayudar a sus hijos a desarrollar hábitos de alimentación sana, para toda la vida. Ofrecer una variedad de comidas ayuda a los niños a obtener los nutrientes que necesitan de cada grupo de alimentos. También tendrán mayores probabilidades de querer probar alimentos nuevos y que estos les gusten. Cuando los niños desarrollan un gusto por muchos tipos distintos de alimentos, es más fácil planificar las comidas de la familia. ¡Cocinen juntos, coman juntos, hablen y hagan que las comidas sean tiempos dedicados a la familia!

1

eduque con su ejemplo

Coma vegetales, frutas y granos integrales en las comidas o como bocadillos. Deje que su hijo vea que a usted le gusta comer vegetales frescos.

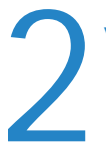
vayan de compra juntos Ir de compras de comestibles puede educar a sus hijos sobre los alimentos y la nutrición. Hablen sobre de dónde provienen los vegetales, las frutas, los granos, los productos lácteos y las proteínas.

Permita que sus hijos tomen decisiones saludables.
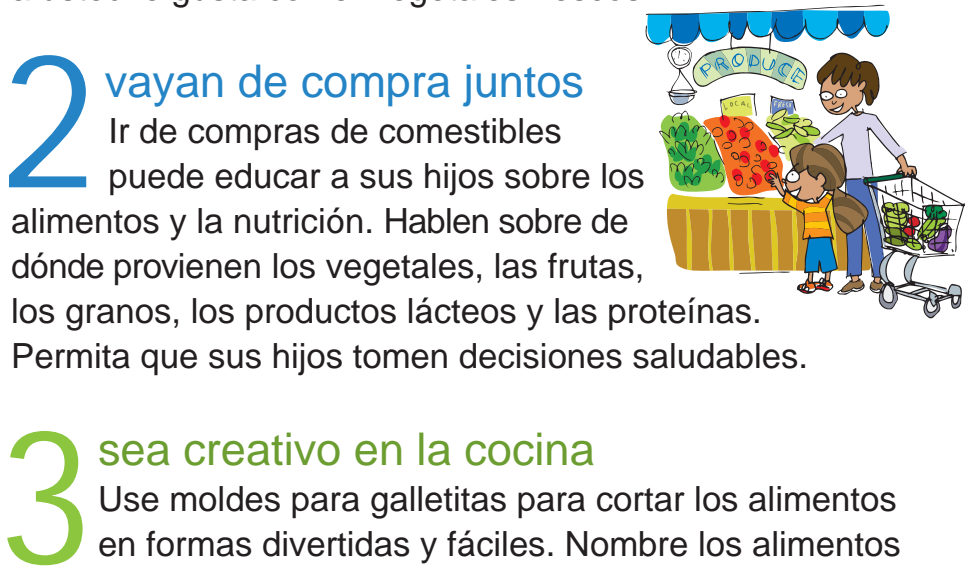

\section{sea creativo en la cocina}

Use moldes para galletitas para cortar los alimentos en formas divertidas y fáciles. Nombre los alimentos que sus hijos ayuden a preparar. Sirva la "ensalada de Janie" o los "camotes de Jackie" a la cena. Anime a sus hijos a inventarse bocadillos nuevos. Prepare sus propias mezclas de nueces y frutas con granos integrales secos, cereales con bajo contenido de azúcar y frutas secas.

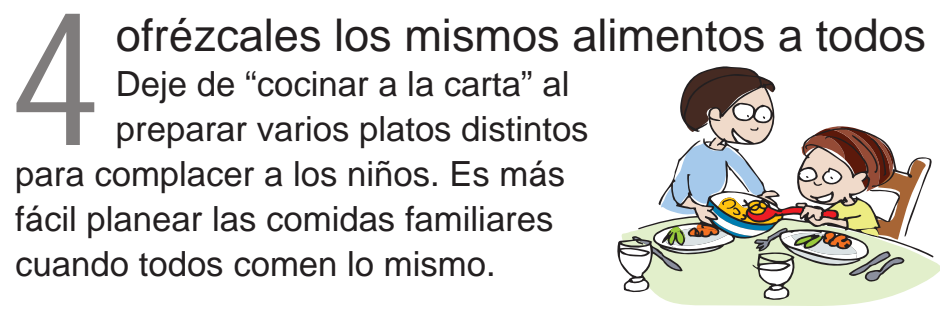

\footnotetext{
recompense con atención, no con comida Demuestre su amor con abrazos y besos. Consuele con abrazos y conversaciones. No ofrezca dulces como recompensas. Eso permite que sus hijos comiencen a pensar que los postres son mejores que otros alimentos. Si no se comen la comida, los niños no necesitan "otras cosas", como dulces o galletitas, para reemplazarla.
}

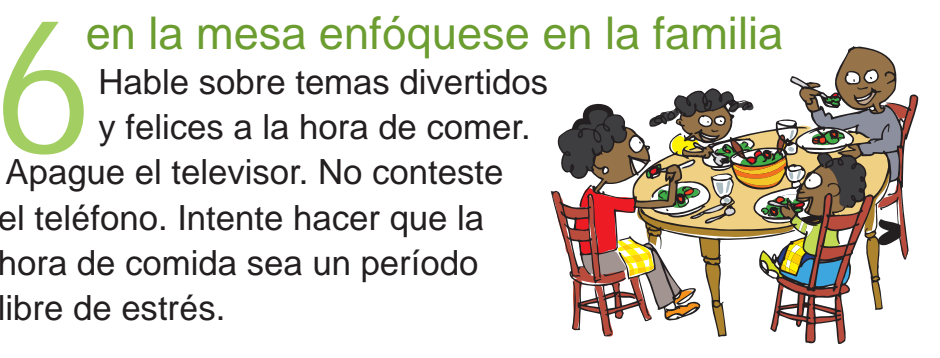

7 preste atención a sus hijos Si sus hijos dicen que tienen hambre, ofrézcales bocadillos pequeños y sanos, aunque no sea hora de comer. Ofrezca opciones. Pregunte “¿Qué les gustaría en la cena: brócoli o coliflor?" en lugar de decir "¿Quieren brócoli con la cena?"

\section{- limite el tiempo frente a una pantalla No permita más de 2 horas al día frente a la tele- visión o la computadora. Levántese y muévase} durante los anuncios para hacer algo de actividad física.
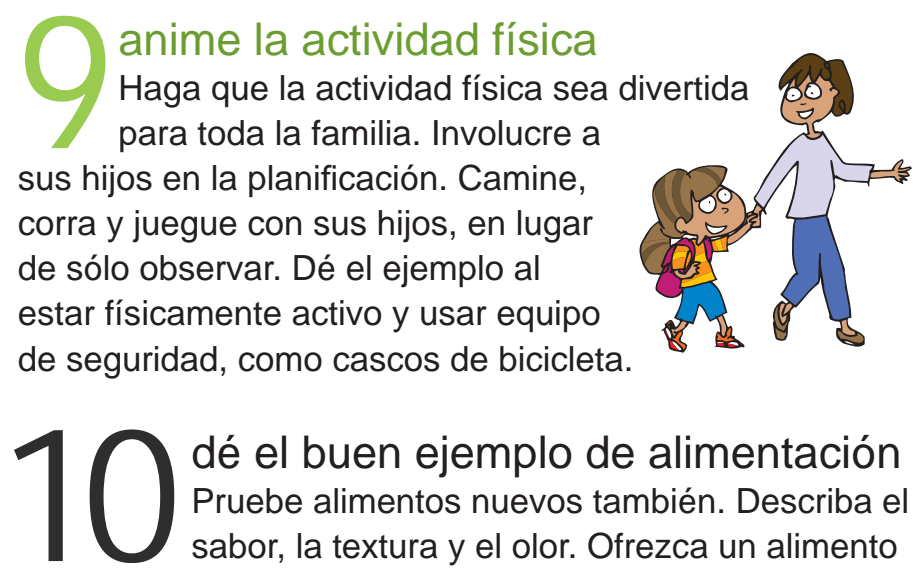
dé el buen ejemplo de alimentación Pruebe alimentos nuevos también. Describa el sabor, la textura y el olor. Ofrezca un alimento nuevo a la vez. Sirva un alimento nuevo con algún otro que les guste a sus hijos. Ofrezca alimentos nuevos al empezar a comer, cuando sus hijos tienen mucha hambre. Evite las discusiones o el forzar a sus hijos a comer.

DG TipSheet No. 12 Septiembre 2011 Distribuido por UF/IFAS Extensión Visite www.ChooseMyPlate.gov para obtener más información.

\section{EL USDA es un proveedor y empleador que ofrece igualdad de oportunidades para todos.}




\section{0 \\ consejos Serie \\ de educación en nutrición}

\section{Reduzca el consumo de golosinas de sus hijos}

10 consejos para reducir el azúcar adicional

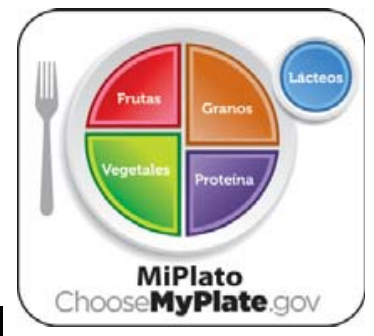

Limite la cantidad de alimentos y bebidas endulzadas que sus hijos comen y beben. Si no los compra, sus hijos no los beberán muy a menudo. Las golosinas y las bebidas endulzadas tienen muchas calorías pero pocos nutrientes. La mayoría de los azúcares adicionales provienen de gaseosas, bebidas deportivas, bebidas de energía, bebidas a base de jugo, pasteles, galletas dulces, helados, dulces y otros postres.

1 sirva porciones pequeñas

No es necesario eliminar completamente los dulces y os postres, pero enseñe a sus hijos que las golosinas en cantidades pequeñas son suficientes. Use tazones y platos más pequeños para servir esos alimentos. Permita que sus hijos compartan una barra de dulce o un bizcocho grande.

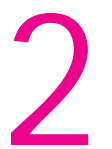
beba juiciosamente Las gaseosas y otros refrescos dulces contienen mucho más azúcar y más calorías. Cuando sus hijos tengan sed ofrézcales agua, 100\% jugo o leche descremada.

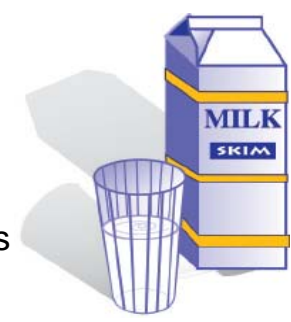

\section{Uuse la cajera que no tenga dulces}

La mayoría de los supermercados tienen cajeras sin dulces para ayudar a las madres. La espera en la fila para pagar anima a los niños a pedir los tentadores dulces que les rodean.

\section{no ofrezca dulces como recompensas}

Al ofrecer alimentos como recompensas del buen comportamiento, los niños aprenden a pensar que algunos alimentos son mejores que otros. Recompense a sus hijos con palabras cariñosas y abrazos de consuelo, u ofrézcales otros artículos no comestibles como calcomanías para que se sientan especiales.

\section{haga que las frutas sean el} postre de todos los días Sirva manzanas o peras asadas, o ensalada de frutas. También sirva sabrosas barras de jugo congelado (100\% jugo) en lugar de postres con alto contenido de calorías.

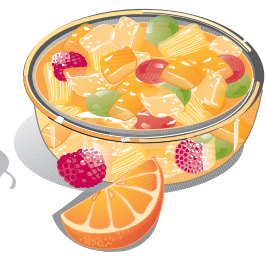

haga las comidas divertidas

Las golosinas para los niños se comercializan como "comidas divertidas." Haga que las comidas nutritivas sean divertidas al prepararlas con ayuda de sus hijos y de manera creativa. Invente una cara sonriente con rebanadas de plátano y pasas. Use moldes para galletitas para cortar las frutas en formas divertidas y fáciles.

\section{anime a sus hijos a inventarse bocadillos nuevos \\ Prepare sus bocadillos con cereales secos de granos integrales, frutas secas y nueces o semillas sin sal. Provea los ingredientes y permita que los niños elijan lo que quieren preparar como

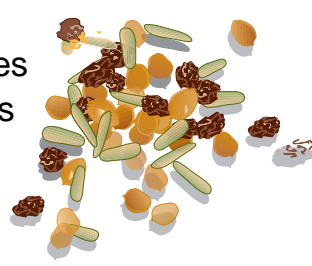
bocadillo "nuevo."

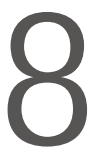

juegue al detective en el estante de cereales

Enseñe a los niños cómo encontrar la cantidad total de azúcar en varios cereales. Anímelos a comparar los cereales que les gustan y a seleccionar el que tenga menos azúcar.

\section{haga que las golosinas sean "especiales" no comidas de todos los días \\ Las golosinas son fabulosas de vez en cuando.} Pero no haga que sean comidas de todos los días. Limite las golosinasy dulces a ocasiones especiales.

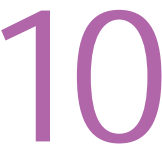

si los niños no se comen sus comidas, no hay que darles dulces "extra" Tenga en mente que los dulces o las galletitas no deben reemplazar los alimentos no consumidos a la hora de comer. 


\section{0 \\ consejos Serie \\ de educación en nutrición

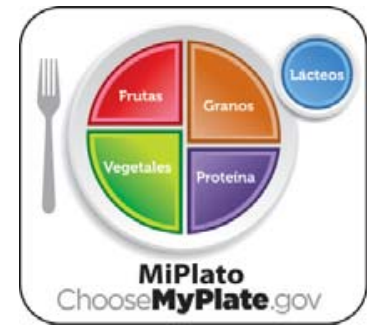

Está claro que a los estadounidenses les gusta la sal, pero la sal influye en la presión arterial alta. Todos, incluso los niños, debemos reducir el consumo de sodio a menos de 2,300 miligramos al día. Los adultos de 51 años de edad y mayores, las personas de ascendencia afroamericana de cualquier edad y con presión arterial alta, diabetes o enfermedad renal crónica deben reducir el consumo de sodio a 1,500 mg al día.

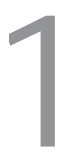

piense en alimentos frescos

La mayor parte del sodio que consumen los estado unidenses proviene de alimentos procesados. Coma alimentos procesados con menos frecuencia y en porciones pequeñas, especialmente alimentos con queso como pizzas, carnes procesadas como tocino, chorizo, salchichas y embutidos, así como alimentos listos para comer como chili, ravioli y sopas enlatadas. Por lo general, los alimentos frescos tienen menos sodio.

disfrute alimentos preparados en casa Cocine en casa con más frecuencia, donde puede controlar los ingredientes de sus comidas. Preparar sus propios alimentos le permite limitar la cantidad de sal.

\section{3} llénese de vegetales y frutas, son naturalmente bajas en sodio

Coma cantidades abundantes de vegetales y frutas, frescas o congeladas. Coma una fruta o vegetal con cada comida.

\section{elija productos lácteos y proteínas con el
contenido más bajo de sodio
Elija leche o yogur descremados o con bajo contenido} de grasa más frecuentemente que queso, que contiene más sodio. Elija carne de res, cerdo, aves, pescados y mariscos frescos, en lugar de los procesados con sal. Los embutidos, salchichas y productos enlatados, tienen un alto contenido de sodio. Elija nueces y semillas sin sal.

\section{ajuste su paladar}

Reduzca la sal que consume gradualmente, y preste atención al sabor natural de varios alimentos. Con el tiempo, su gusto por la sal se reducirá.

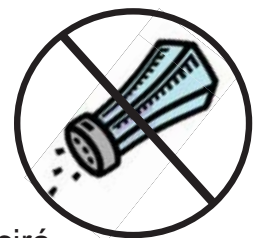




\section{0 \\ consejos \\ Serie \\ de educación \\ en nutrición \\ coma productos marinos dos veces a la semana \\ 10 consejos para ayudarle a comer más productos marinos

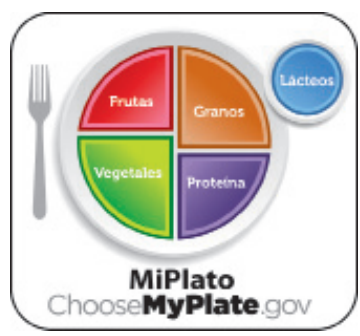

Prepare pescado y mariscos dos veces por semana como el principal alimento fuente de proteínas en su plato.* Los productos marinos contienen variedad de nutrientes, incluyendo grasas saludables como omega-3, de acuerdo con la Guía Alimentaria para los estadounidenses del 2010 comer unas 8 onzas por semana (menos para los niños pequeños) puede ayudar a prevenir las enfermedades cardiacas.

coma variedad de productos marinos Incluya algunos que tengan alto contenido de omega-3 y menor contenido de mercurio como: salmón, trucha, ostras, caballa del Atlántico o del Pacífico, arenques y sardinas.

\section{manténgalos bajos en grasas y sabrosos}

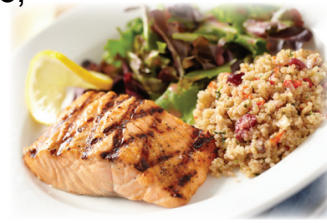

Prepárelos asados, a la parrilla, o horneados. Evite el apanado o la fritura de los productos marinos y las salsas de crema, ya que estos añaden calorías y grasa. Utilice especias y hierbas, como eneldo, ají en polvo, pimentón, comino y/o jugo de limón, para añadir sabor sin agregar sal.

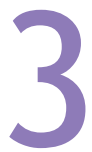

\section{¡los mariscos también cuentan!}

Las ostras, los mejillones, las almejas y los calamares suministran omega-3. Pruebe mejillones, estofado de ostras, almejas al vapor o pasta con calamares.

\section{mantenga los productos}

\section{marinos a la mano}

El pescado enlatado como salmón, atún o sardinas, se puede usar de manera rápida y fácil. El atún blanco enlatado tiene más omega-3, pero el atún "light" enlatado tiene menos niveles de mercurio.

\section{5} cocine de manera segura

Antes de cocinar, compruebe la frescura de las ostras, mejillones y almejas. Descártelas si las conchas crudas no se cierran al tocarlas o si después de cocinarlas no se abrieron. Esto significa que es posible que no sea seguro para comerlas. Cocine los camarones, las langostas y las vieiras hasta que estén blancas lechosas. Cocine el pescado a $145^{\circ} \mathrm{F}$, hasta que se deshaga con el tenedor.

* Esta recomendación no se aplica los vegetarianos. de rienda suelta a su creatividad con los productos marinos

Pruebe las hamburguesas de salmón, camarones salteados, tacos de pescado a la plancha o almejas con pasta integral. Agregue variedad probando un nuevo pescado como caballa a la plancha, arenque en una ensalada o abadejo horneado.

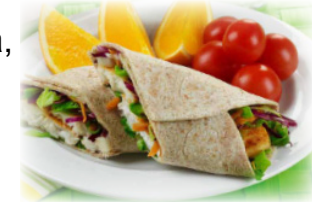

\section{Póngalos en una ensalada o en un sándwich}

Ponga a las ensaladas cangrejo, camarones o vieiras a la plancha en lugar de bistec o pollo. Utilice conservas de atún o salmón para los sándwiches en lugar de embutidos, que a menudo tienen más alto contenido de sodio.

\section{compras inteligentes}

Comer más productos marinos no tiene que ser caro. La pescadilla, la tilapia, las sardinas, el atún enlatado y algunos productos marinos congelados son generalmente opciones de menor costo. Para ayudarle a ahorrar dinero en productos marinos busque ventas con descuento, cupones y ofertas especiales en el periódico local, internet y tiendas.

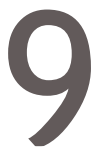
crezca saludable con los productos marinos Las grasas omega-3 de los productos marinos pueden ayudar a mejorar el desarrollo del sistema nervioso en los lactantes y niños. Sirva productos marinos a los niños dos veces por semana en porciones adecuadas para su edad y apetito. Productos marinos bajos en mercurio también deben formar parte de la dieta para mujeres embarazadas o amamantando.

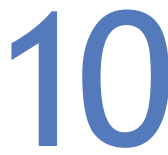
conozca las porciones de los productos de mar Utilice la siguiente guía para obtener 8 onzas de productos marinos: una lata de atún escurrida tiene aproximadamente de 3 a 4 onzas, un filete de salmón pesa de 4 a 6 onzas y 1 trucha pequeña pesa alrededor de 3 onzas. 


\section{0 \\ consejos \\ Serie \\ de educación \\ en nutrición \\ coma mejor dentro del presupuesto \\ 10 consejos para ayudarle a que los dólares para la comida le rindan

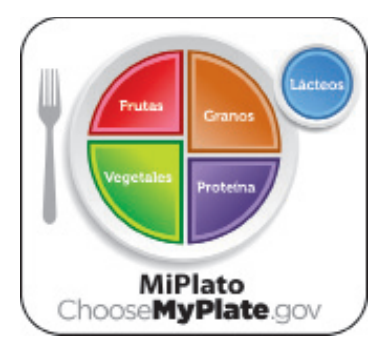

¡Haga rendir su presupuesto de comidas! Hay muchas maneras de ahorrar dinero en la comida. Los tres pasos principales son planificar antes de comprar, comprar los artículos al mejor precio y preparar comidas que hagan rendir su presupuesto.

\section{1}

planificar, planificar, planificar

Antes de dirigirse al supermercado, planifique sus comidas de la semana. Incluya comidas como guisos, cazuelas o frituras, las cuales hacen rendir los productos caros en más porciones. Verifique que ingredientes tiene y haga una lista de los que necesita comprar.

\section{obtenga el mejor precio}

Busque ofertas y cupones en el

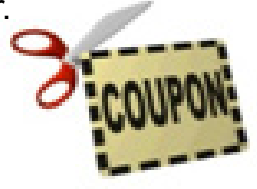

periódico local, internet o supermercados. Para lograr ahorros adicionales pregunte por tarjetas de afiliado en la tienda donde hace sus compras. Busque ofertas en carnes y productos marinos, los cuales a menudo son los productos más caros de su lista.

\section{3} compare y busque diferencias Busque el "precio unitario" mostrado en el estante, directamente debajo del producto. Utilícelo para comparar diferentes marcas y tamaños del mismo producto y determinar cuál es el más económico.

\section{4} compre a granel

Casi siempre es más barato comprar alimentos a granel. Por ejemplo los paquetes familiares de pollo, filete o pescado, bolsas de papa grandes y vegetales congelados. Antes de comprar, recuerde verificar si tiene suficiente espacio en el congelador.

\section{5} compre de acuerdo con la estación Comprar frutas y vegetales de temporada puede disminuir el costo y añadir productos frescos. Si no va a utilizarlas inmediatamente, compre las que necesitan tiempo para madurar.

\section{costos de conveniencia...}

\section{regrese a lo básico}

Los alimentos procesados como cenas congeladas, vegetales cortados y arroz, avena o sémola instantáneos o pre-cocidos le costarán más. Ahorre preparándolos usted misma.

\section{7} impacto en su bolsillo Ciertos alimentos son opciones de bajo costo durante todo el año.

Ensaye con los frijoles para obtener comidas baratas con proteínas. En cuanto a vegetales, compre zanahorias, verduras o papas. En cuanto a las frutas, las manzanas y los plátanos son buenas opciones.

cocine todo de una vez...coma durante toda la semana

Preparare lotes grandes de sus recetas favoritas en su día libre (doble o triplique la receta). Congele en recipientes individuales. Utilícelos durante toda la semana y no tendrá que gastar dinero en comidas para llevar.

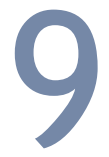

\section{ponga a fluir sus jugos creativos} Utilice las sobras en nuevas formas. Por ejemplo, pruebe el pollo sobrante frito, en una ensalada o haga ají de pollo. Recuerde, desechar alimentos es tirar el dinero.

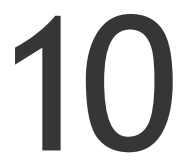

\section{comer afuera}

Los restaurantes pueden resultar caros. Ahorre dinero obteniendo promociones especiales, salga a almorzar en lugar de ir a cenar, o busque ofertas de "2 por 1." Pida agua en lugar de otras bebidas, las cuales suman a la cuenta final.
DG TipSheet No. 16 Diciembre 2011

EL USDA es un proveedor y empleador que ofrece igualdad de oportunidades para todos. 


\section{0 consejos Serie de educación en nutrición}

\section{use SuperTracker a su manera} 10 consejos para empezar

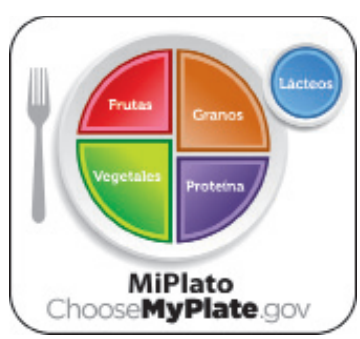

\section{SuperTracker es una herramienta en internet donde se puede obtener un plan personalizado de actividades} y nutrición. Establezca el recor de lo que come y de sus actividades para ver cómo se integran, y obtenga consejos y apoyo para ayudar a tomar decisiones saludables. El "SuperTracker está disponible sólo en inglés.

\section{cree un perfil}

Introduzca información acerca de usted en la página

"Create Profile" para obtener un plan personal de alimentos y su límite de calorías; regístrese para guardar sus datos y tener acceso en cualquier momento.

\section{compare alimentos}

Consulte "Food-A-Pedia" para buscar

información de nutrición de más de 8,000

alimentos y compárelos unos con otros.

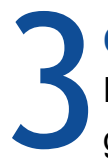

obtenga su plan

En "My Plan" podrá ver sus metas diarias para cada grupo de alimentos; qué y cuánto debe comer dentro de las calorías que tiene asignadas.

\section{4} realice un seguimiento de sus actividades y alimentos

Use el "Food Tracker" y el "Physical Activity Tracker" para buscar en una base de datos de más de 8,000 alimentos y casi 800 actividades físicas y vea cómo sus opciones diarias se integran con respecto a su plan; guarde sus favoritos y copie para una entrada fácil.

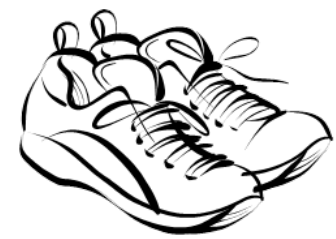

\section{construya un combo}

Ensaye "My Combo" para enlazar y guardar alimentos que suele comer juntos, de manera que pueda agregarlos a las comidas con un solo clic.

\section{ejecute un informe}

Vaya a "My Report" para medir el progreso; elija entre seis informes que van desde un simple resumen de comida a un análisis profundo del grupo de alimentos y nutrientes ingeridos en un tiempo determinado.

\section{establezca una meta}

Explore "My Top 5 Goals" para elegir hasta cinco metas personales que desee lograr. Regístrese en "My Coach Center" para obtener consejos y apoyo mientras trabaja para lograr sus objetivos.

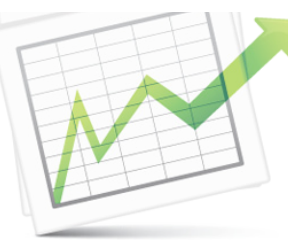




\section{0 \\ consejos \\ Serie \\ de educación en nutrición \\ disfrute de sus alimentos, pero coma menos \\ 10 consejos para disfrutar de sus comidas

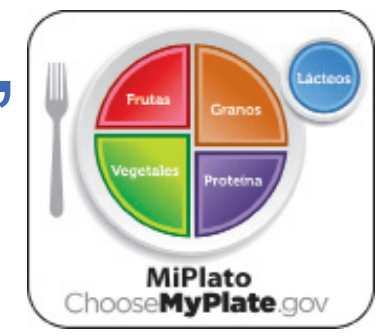

Puede disfrutar de sus comidas mientras hace pequeños ajustes a las cantidades de alimentos en su plato. Las comidas saludables empiezan con más vegetales, frutas, y porciones más pequeñas de proteínas y granos. No olvide los lácteos: incluya productos lácteos sin grasa o bajos en grasa en sus comidas, o beba leche con su comida.

\section{conozca los alimentos que ingiere}

Utilice el "Super Tracker" para averiguar cuánto y qué tipos de alimentos debe comer, también para obtener consejos y apoyo para hacer la mejor elección de alimentos.

\section{tómese el tiempo necesario}

Tenga presente que debe comer despacio, disfrute del sabor y las texturas y preste atención a cómo se siente. Use las señales de hambre y saciedad para reconocer cuándo comer y si ha tenido suficiente.

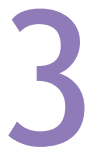

\section{use un plato más pequeño}

Utilice platos más pequeños en las comidas para ayudar con el control de las porciones. Así puede terminar su plato completo y sentirse satisfecho sin comer en exceso.

\section{Si come fuera, elija las opciones más saludables}

Compruebe y compare la información nutricional sobre los alimentos que está comiendo. La preparación de los alimentos en el hogar hace más fácil controlar los ingredientes de sus comidas.

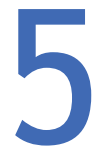

\section{satisfaga sus deseos de comer algo} dulce de manera saludable

Disfrute de un postre endulzado naturalmente, como las frutas. Sírvase un coctel de frutas fresco o con yogur. Para un postre caliente, hornee manzanas y remate con canela encima.

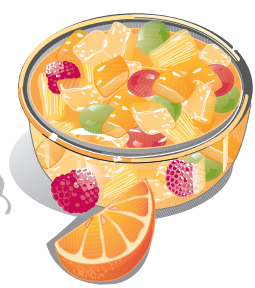

\section{elija comer algunos alimentos con más} o menos frecuencia

Elija más vegetales, frutas, granos enteros y leche descremada o productos lácteos bajos en grasa (1\%). Disminuya el consumo de alimentos con alto contenido de grasas sólidas, azúcares añadidos y sal.

\section{1 (}

\section{encuentre lo que necesita}

Obtenga su plan personalizado utilizando el "Super Tracker" para identificar sus metas para cada grupo de alimentos.

Compare los alimentos que come con los alimentos que necesita comer.

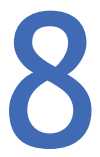
beba de forma inteligente Cuando este sediento tome agua o bebidas libres de calorías, $100 \%$ jugo de frutas o leche sin grasa. Las gaseosas o refrescos y otras bebidas dulces contienen mucha azúcar y tienen un alto contenido de calorías.

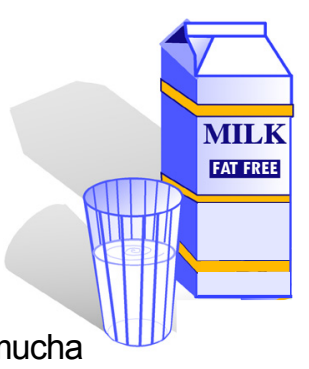

\section{9}

compare alimentos

Consulte "Food-A-Pedia" para buscar y comparar la información nutricional de más de 8,000 alimentos.

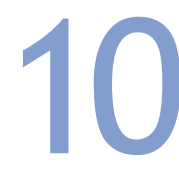

haga que las golosinas sean "golosinas," no comidas cotidianas Las golosinas son buenas de vez en cuando. No trate de convertirlas en su alimento diario. Restrinja las golosinas dulces para ocasiones especiales. 


\section{0 \\ consejos \\ Serie \\ de educación \\ en nutrición \\ seleccione sus bebidas saludablemente 10 consejos para empezar

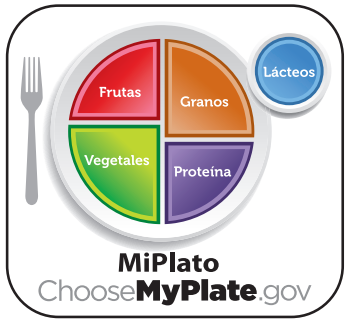

Lo que bebes es tan importante como lo que comes. Muchas bebidas contienen azúcar y ofrecen pocos o casi ningún nutriente, mientras que otras contienen nutrientes pero mucha grasa y también muchas calorías. Aquí presentamos algunos consejos para ayudarte a seleccionar mejor tus bebidas.

\section{bebe agua}

Cuando tengas sed, bebe agua en vez de bebidas azucaradas. Las gaseosas o refrescos, bebidas energéticas y otras bebidas azucaradas contienen mucha azúcar, estas bebidas contienen más calorías de las que necesitas. Para mantener un peso saludable bebe agua u otras bebidas sin o con pocas calorías.

\section{cuánta agua es suficiente?}

Deja que tu sed te guíe. El agua es un nutriente importante para el cuerpo, pero cada uno tiene necesidades diferentes. Muchos de nosotros adquirimos agua suficiente de los alimentos y las bebidas que consumimos. Un cuerpo saludable puede balancear los requerimientos de agua. Bebe abundante agua si eres muy activo, si vives o trabajas en condiciones calurosas, o si eres de la tercera edad.

\section{una opción barata}

El agua es usualmente barata. Puedes ahorrar dinero tomando agua potable de la casa o cuando vas a comer fuera.

\section{4}

\section{maneje sus calorías}

Beba agua con las comidas y entre las comidas. Los adultos y los niños beben cerca de 400 calorías por día, beber agua podría ayudarte a manejar tus calorías.

\section{3}

\section{zona de bebidas para niños}

Haz que el agua, la leche sin o baja en grasa, o los jugos $100 \%$ de frutas sean una opción fácil en casa. Prepara y ten listos en el refrigerador

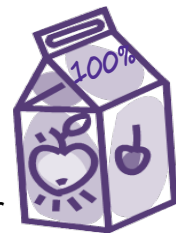
botellas de agua o bebidas saludables para cuando salgas de casa, guárdalos en las mochilas o las loncheras de los niños. Dependiendo de la edad, los niños pueden beber de $1 / 2$ a 1 taza de jugo* $100 \%$ de frutas o vegetales al día y los adultos pueden beber hasta una taza.

*Jugo $100 \%$ es parte del grupo de las frutas y vegetales. Los jugos deben constituir la mitad o menos de la recomendación para el grupo de frutas y vegetales.

\section{no olvides tu leche**}

Cuando tomes leche $u$ otras bebidas alternativas, selecciona leche sin o baja en grasa, o leche de soya fortificada. Cada tipo de leche ofrece la misma cantidad de nutrientes como calcio, vitamina $D$, y potasio, pero el número de calorías varía. Los niños mayores, adolescentes y adultos necesitan 3 tazas de leche por día, los niños de 4 a 8 años de edad $2 \frac{1}{2}$ tazas y los niños de 2 a 3 años 2 tazas.

\section{disfruta tu bebida}

Cuando no desees agua, disfruta tu bebida favorita pero en pocas cantidades. Recuerda chequear el número de porciones en la etiqueta de la lata, botella o vaso para mantener las calorías que necesitas. Selecciona envases pequeños en vez de los grandes.

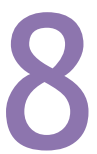

\section{agua para el camino}

El agua es siempre conveniente. Llena una botella reusable limpia con agua y ponla en tu bolsa para cuando estés sediento.

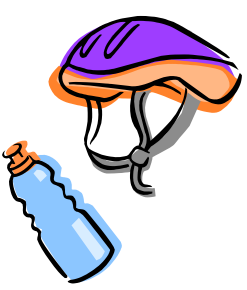
Las botellas reusables también protegen el medio ambiente.

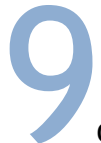

\section{chequea la información de la etiqueta}

La etiqueta contiene información nutricional sobre la cantidad total de azúcares, grasas y calorías, úsalas para escoger mejor tus bebidas.

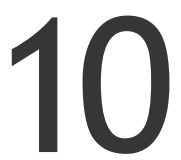

\section{compara los nutrientes de tus bebidas}

Food-A-Pedia, es una opción disponible online en ChooseMyPlate.gov/SuperTracker, para ayudarte a comparar las calorías, azúcares y grasas de tus bebidas favoritas. (Food-a-pedia y SuperTracker están disponibles sólo en inglés.)

\footnotetext{
** La leche es parte del grupo de los lácteos. Una taza = 1 taza de leche o yogur, $1 \frac{1}{2}$ onza de queso natural, o 2 onzas de queso procesado.
} 


\section{0 \\ consejos Serie de educación Haz que las celebraciones sean divertidas, saludables y activas en nutrición

\section{E Comer saludablemente y mantenerse físicamente activo puede ser la parte divertida de las}

fiestas y eventos. Las celebraciones fantásticas puden ser fáciles de organizar si presentamos alimentos, saludables y deliciosos, de todos los grupos de alimentos en forma divertida. Pero sobre todo disfrute de la compañía de los amigos y de la familia.

\section{1}

\section{haz que los hábitos saludables sean} parte de las celebraciones

Los alimentos y las bebidas son parte de los eventos, pero no tienen que ser el centro de la reunión. Enfóquese en las actividades para mantener a la gente moviéndose y gozar de su compañía.

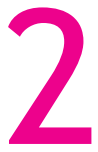

\section{haz que las comidas se} vean festivas

Decore los platos con nueces y semillas, o sirva los vegetales en formas nuevas. Adicione frutas vistosas para sus platos favoritos, sirva una receta nueva, or esparza almendras o cebollas verdes para adicionar algo decorativo.

\section{3}

\section{refrésquese con sabor}

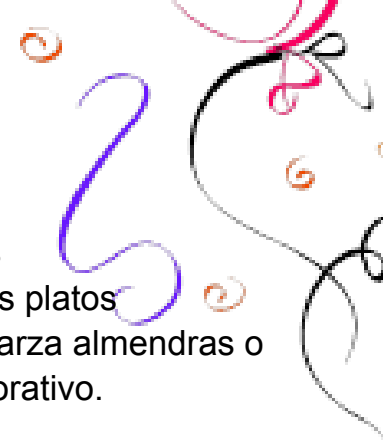

Prepare cubos congelados de jugo $100 \%$ de frutas o addicione pedazos de fruta para hacer el agua más acceptable. Invente un "flotante" adicionando una cuchara o porción de helado, bajo en grasa, en un vaso de agua con gas.

\section{salve el savor}

Ponga atención a cada bocado de la comida. Haga pequenos cambios en sus recetas antiguas o prepare platos de otras regiones para avivar las comidas.

\section{3}

\section{use ChooseMyPlate.gov para incluir} alimentos de todos los grupos de alimentos para su fiesta

Ofrezca galletas integrales, sirva crema hecha de frejoles picantes y bandejas de vegetales, prepare kebabs de fruta, o copas con capas de yogur y frutas para crear una ensalada de frutas. Use granos integrales y vegetales para crear ensaladas saludables y llenas de sabor.

\section{cree la hora de la movida para cada reunión}

El estar físicamente activo le hace sentir bien a cualquiera. Bailar, moverse, jugar y reir adicionan diversión a la reunión.

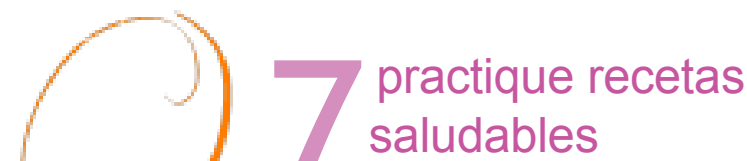

\section{saludables}

Encuentre maneras de bajar el azúcar, sal, y grasas cuando prepare sus recetas favoritas. Practique las recetas de ChooseMyPlate.gov.

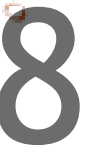

manténgalo simple

Haga participar a otros, haciéndolos preparar platos, ayudando a limpiar o ayudando a matener a los niños activos.

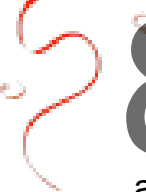

\section{compre para comer inteligentemente} Ahorre dinero ofreciendo comidas que esten dentro de su presupuesto. Compre los productos cuando esten de temporada, cuando los precios esten bajos y los productos esten frescos y jugosos. Planifique con anticipación y compre productos en oferta.

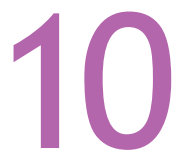

\section{sea el animador de hábitos}

\section{saludables}

Nunca es muy temprano para que los adultos demuestren a los niños buenos hábitos con el ejemplo. Tenga presente que los niños imitan a los adultos que estan cerca de ellos, incluso en las fiestas.

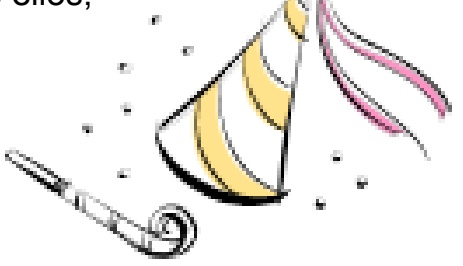




\section{0 \\ consejos Serie de educación en nutrición}
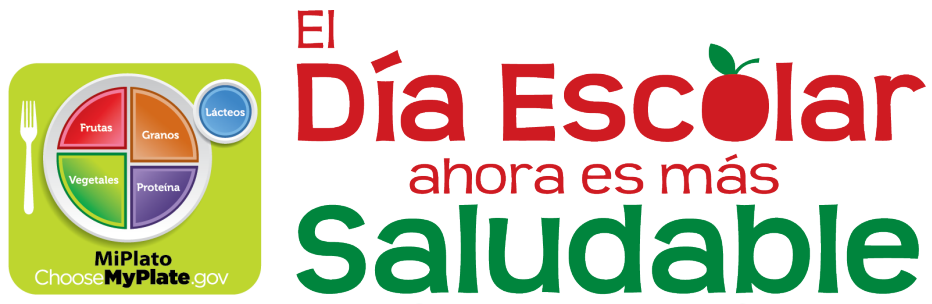

United States Department of Agriculture

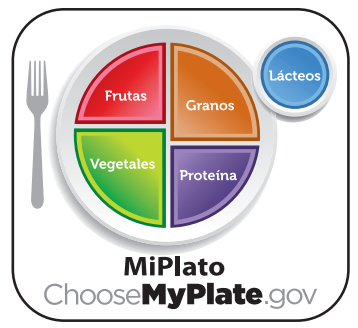

Cerca de 32 millones de niños reciben comidas a través del comedor escolar. Estas comidas estan basadas en estandares nutricionales emitidos por el Departamento de Agricultura de los EEUU. Los estandares nutricionales para los comedores escolares incrementan el acceso a alimentos nutritivos y animan a los niños a seleccionar comidas saludables. Los centros escolares estan trabajando para hacer las comidas más nutritivas, a mantener a los estudiantes sin hambre, y ayudar a los niños a mantener o alcanzar un peso saludable.

\section{comidas escolares saludables}

Sus niños se benefician con comidas saludables que incluyen granos integrales, frutas y vegetales, productos lácteos bajos en grasa, alimentos bajos en sal y menos grasas saturadas. Hable con su niño(a) sobre los cambios en las comidas que se estan sirviendo en los colegios.

\section{2}

\section{más frutas y vegetales cada día}

Los niños disponen de frutas y vegetales cada día.

Una gran variedad de vegetales son servidos durante la semana, incluyendo verduras y otros vegetales rojos y anaranjados.

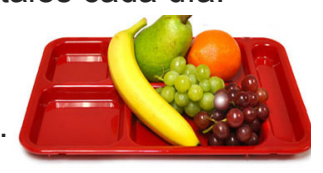

\section{más granos integrales}

La mitad de los cereals ofrecidos son productos

integrales como por ejemplo: pasta de harina integral, arroz integral y avena. Algunos productos son hechos remplazando la mitad de la harina refinada por harina integral.

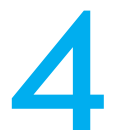

\section{leche sin grasa y baja en grasa} $(1 \%)$ son ofrecidos

Al tomar leche sin grasa o baja en grasa (1\%), los niños adquieren la misma cantidad de calcio y otros nutrientes pero con pocas calorías y menos grasas saturadas. Para los niños que no pueden tomar leche debido a alergias o por ser intolerantes a la lactosa, los colegios pueden ofrecer sustitutos de leche como por ejemplo bebidas de soya fortificadas con calcio.

\section{menos sal y menos grasas saturadas}

Variedad de alimentos son ofrecidos para reducir la sal y las grasas saturadas en las comidas escolares. Las comidas principales pueden incluir frejoles, alverjitas,

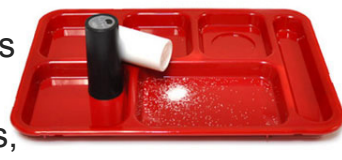
nueces, tofu o pescado, así como carnes magras y pollo. Los ingredients y comidas contienen menos sal (sodio).

\section{más agua}

Los centros escolares pueden proveer agua en jarras y en vasos para las bandejas de almuerzo, también habrá agua disponible en fuentes o caños para permitir que los estudiantes llenen sus vasos y botellas con agua para beber. El agua estará disponible en los comedores escolares.

\section{7 nuevos tamaños de porciones}

Las comidas escolares satisfacen las necesidades calóricas de los niños de acuerdo a su edad. Mientras algunas porciones pueden ser pequeñas, éstas aún satisfacen las necesidades nutricionales de los niños para que sigan creciendo y se mantengan activos.

\section{fortalecer los programs locales de salud}

Las nuevas regulaciones ofrecen oportunidades

para que los padres de familia y las comunidades puedan crear programas de salud y promoción social que permitan satisfacer las nececidades locales. Hable con el coordinador del centro escolar, maestros, asociación de maestros y padres de familia, y otros para crear programas de salud en su comunidad.

\section{MiPlato puede ayudar a sus niños} a escoger mejor sus alimentos

Muestre a los niños cómo elegir sus alimentos saludablemente en el colegio usando MiPlato. Visite ChooseMyPlate.gov para consejos y otros recursos.

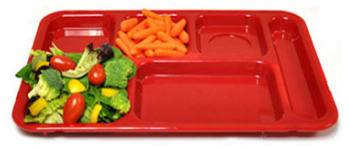

\section{recursos para los padres}

Los programas de alimentos escolares pueden proveer mucho de lo que los niños necesitan para crecer saludables. Sin embargo para muchos padres comprar alimentos saludables es difícil. Infórmese más sobre comedores escolares saludables y otros programas de nutrición en www.fns.usda.gov.

Distribuido por UF/IFAS Extensión

Visite www.ChooseMyPlate.gov para obtener más información.
Agosto 2012

EI USDA es un proveedor y empleador que ofrece igualdad de oportunidades para todos. 


\section{0 \\ consejos \\ Serie \\ de educación \\ escoja productos \\ integrales \\ en nutrición}

\section{0 consejos para comprar y guardar alimentos integrales}

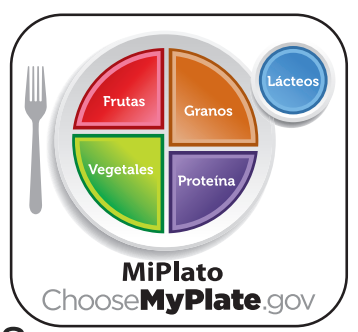

Los productos integrales son fuentes importantes de nutrientes como zinc, magnesio, vitamina B, y fibra. Hay muchas alternativas para hacer que la mitad de los cereals que consumes sean integrales (whole). Pero, los productos integrales tienen que ser manipulados con cuidado. Los aceites de productos integrales pueden deteriorarse con el tiempo, si no estan adequadamente almacenados. Considere los siguientes consejos para mantener sus productos integrales frescos y seguros para comer.

\section{revise la etiqueta}

Los productos integrales pueden ser una alternativa fácil cuando prepare sus alimentos. Escoja panes, cereales, y otros productos integrales. Revise la etiqueta para encontrar opciones bajas en

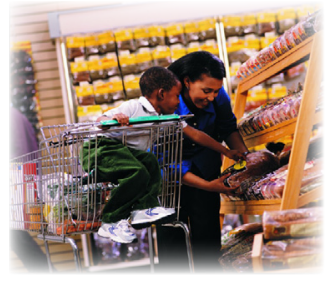
sodio, grasas saturadas (sólidas) y azúcar.

\section{asegúrese que la palabra "whole" este} al comienzo de la lista de ingredients

Algunos productos integrales incluyen avena integral, harina integral de trigo, maíz de grano entero, arroz integral, arroz silvestre, centeno integral. Productos que dicen "multi-grain," "100\% wheat," "high fiber," o que son marrones no necesariamente son productos integrales.

\section{los niños pueden escoger productos integrales \\ Los estandares nutricionales actuales permitirán} que los niños puedan escoger productos integrales en los comedores escolares. Usted puede ayudar a que su niño adopte los cambios adicionando poco a poco productos integrales en sus recetas favoritas, comidas y refrigerios.

\section{encuentre la fibra}

Si el producto ofrece por lo menos 3 gramos de fibra por porción servida es una fuente buena de fibra.

Si contiene 5 o más gramos de fibra por porción servida es una fuente excelente de fibra.

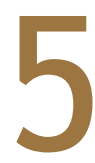

\section{el gluten esta en los productos} integrales?

Escoja sus productos integrales cuidadosamente. Hay muchos productos integrales como alforfón, avena sin gluten, popcorn, arroz integral y quinua que estan incluidos en dietas libres the gluten.

\section{chequee la frescura}

Compre productos integrales que esten bien empacados y sellados. Los granos deben verse y oler frescos. No olvide chequear la fecha de expiración y las recomendaciones para almacenar que estan en el empaque.

\section{$\nabla$} manténgalos herméticamente tapados Cuando almacene productos integrales use embases herméticos y manténgalos en lugares frescos, y secos. Un embase hermético es importante para mantener la frescura y reducir la posibilidad de infestación por gusanos.

\section{compre lo que necesita}

Compre cantidades pequeñas de productos integrales para reducir la pérdida por deterioro. Muchos de los granos pueden ser almacenados en el refrigerador.

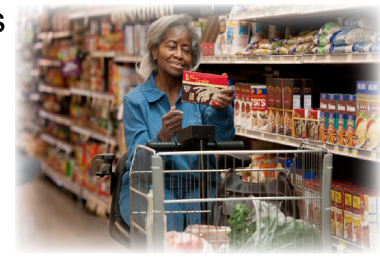

\section{empaquételos}

Es mejor almacenar el pan integral en su empaque original, ciérrelo herméticamente y ajústelo con un clip. El refrigerador puede causar la pérdida de la humedad del pan rápidamente y endurecerlo. Adequadamente empaquetado el pan puede ser almacenado en el refrigerador sin problemas.

\section{0} cual es la vida de almacenamiento? Ya que los niveles de aceite en las harinas integrales varia, la vida en almacén también. La vida en almacén de la harinas está en función del contenido de aceite. En general las harinas integrales se almacenan bien en el refrigerador por 2 o 3 meses y en el congelador por 6 o 8 meses. El arroz integral cocido puede ser refrigerado de 3 a 5 días y congelado por hasta 6 meses. 


\section{0}

consejos

Serie

de educación

en nutrición

\section{sanidad en la alimentación}

10 consejos para reducir el riesgo de enfermedades por contaminación de alimentos

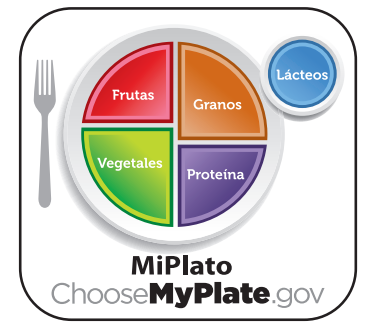

Una parte crítica de la alimentación saludable es mantener la sanidad de los alimentos. Las personas en sus propias casas pueden reducir la posibilidad de contaminar los alimentos siguiendo buenas prácticas al manipular los alimentos. Hay cuatro principios básicos de sanidad alimentaria para reducir el riesgo de contraer enfermedades por contaminación de los alimentos: lavar, separar, cocinar y refrigerar. Estos cuatro principios son la base de "Fight Bac!" ${ }^{\circledR}$ una campaña Nacional para promover sanidad alimentaria para los consumidores y para educarlos en cómo manipular y preparar los alimentos.

\section{LAVAR}

\section{1 lávese las manos con jabón y agua}

Moje sus manos con agua limpia y aplique el jabón.

Use agua caliente si hubiera. Frote sus manos para esparcir el jabón por 20 segundos y asegurarse de limpiar todas las partes de la mano. Enjuage las manos y séqueselas usando una toalla de papel límpia. Si es possible use la toalla de papel para cerrar el caño (pluma) de agua.

\section{2}

\section{sanitize las superficies}

Las superficies deben ser lavadas con agua jabonosa caliente. Para sanitizar las superficies, puede usarse una solución de 1 cuchara de cloro para blanquear sin olor por 1 galón de agua.

\section{limpie la refrigeradora una vez por semana}

Por lo menos una vez por semana, descarte los alimentos de la refrigeradora que no van a ser utilizados. Las comidas recalentadas deben ser descartadas después de 4 días; pollo o carnes de res crudas después de 1 o 2 días.

\section{mantenga los utensilios límpios}

Limpie fuera y dentro de los utensilios. Ponga atención a las uniones y asas o mangos donde pudiera ocurrir contaminación cruzada con las manos.

\section{enjuage los productos frescos}

Enjuage los vegetales y frutas frescas en agua corriente antes de comerlos, cortarlos o cocinarlos. Incluso si planea pelar o cortar antes de comerlos, es muy importante que los enjuague bien para prevenir el transpaso de microbios de la parte externa a la interna de los productos.

\section{SEPARAR}

\section{separe los productos al comprar}

Separe las carnes de pescado, res y aves crudas en bolsas de plástico.En el refrigerador, guarde éstos productos debajo de los productos listos para comer.

\section{separe los productos cuando los prepare o los sirva}

Siempre use una tabla de cortar limpia para los productos frescos y otra para las carnes de pescado, mariscos, res y aves. Nunca ponga alimentos cocidos en el mismo plato o tabla de cortar donde previamente puso carne cruda.

\section{COCINAR Y REFRIGERAR Cuando cocine use un termómetro de alimentos}

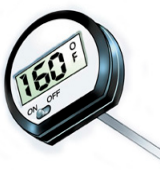

Use un termómetro de alimentos para asegurar que los alimentos hayan sido cocinados a temperaturas seguras y que los alimentos cocidos sean mantenidos a las temperaturas requeridas hasta que sean consumidos.

\section{cocine alimentos hasta lograr temperaturas internas seguras}

Una forma efectiva de prevenir enfermedades por contaminación de los alimentos es chequear la temperatura interna de las carnes de pescado, res, aves, y platos preparados con huevo. Cocine las carnes crudas de res, cerdo, carnero y otros a una temperatura interna mínima de $145^{\circ} \mathrm{F}$. Para seguridad y calidad, espere 3 minutos antes de cortar o comer las carnes. Cocine todas las carnes molidas de res, cerdo, carnero u otros a una temperatura interna de $160^{\circ} \mathrm{F}$. Cocine todas las carnes de aves, incluyendo carne molida de pavo y pollo, a una temperatura interna de $165^{\circ} \mathrm{F}$ (www.isitdoneyet.gov).

\section{mantenga los alimentos preparados a temperaturas seguras \\ Mantenga las alimentos a $40^{\circ} \mathrm{F}$ o por debajo. Mantenga} los alimentos calientes a $140^{\circ} \mathrm{F}$ o por encima. Los alimentos no son seguros para comer si éstos han estado en el rango peligroso de 40-140 ${ }^{\circ} \mathrm{F}$ por más de 2 horas ( 1 hora si la temperature estuvo por encima de los $90^{\circ} \mathrm{F}$ ).

Distribuido por UF/IFAS Extensión

Visite www.ChooseMyPlate.gov para obtener más información. Visite www.fsis.usda.gov para información de sanidad alimentaria.
DG TipSheet No. 23

Octubre 2012 provider and employer. 
10

consejos

Serie

de educación

en nutrición

\section{los refrigerios de MiPlato consejos para los padres}

10 consejos para refrigerios saludables

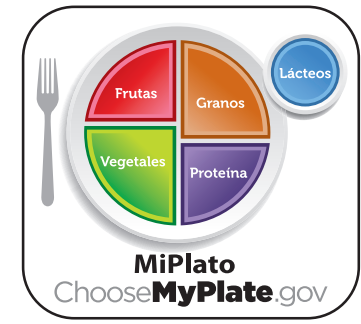

Los refrigerios pueden ayudar a alcanzar el nivel de nutrientes que los niños necesitan para crecer y mantener un peso adecuado. Prepare una porción simple de refrigerio para los mas pequeños para ayudarles a obtener lo necesario para satisfacer su hambre. Deje que los niños mayores preparen sus propios refrigerios con alimentos saludables que usted mantenga en la cocina. Visite ChooseMyPlate.gov para ayudar a los niños y a usted a seleccionar refrigerios que los satisfaga.

\section{ahorre tiempo y corte los vegetales}

\section{previamente}

Guarde vegetales picados en el refrigerador y sírvalos con cremas para untar como crema de garbanzo o salsas bajas en grasa. Decore los panecillos ingleses de trigo integral con salsa para espagueti, vegetales picados, y con queso mozzarella rallado y derretido en el microondas.

\section{mezcle}

Para niños mayores en edad escolar mezcle frutas secas, nueces sin sal y popcorn en una bolsa pequeña de refrigerio para preparar rapidamente una mistura de nueces. Licue yogur natural sin o bajo en grasa con $100 \%$ jugo de frutas y durazno congelado para preparar un sabroso batido.

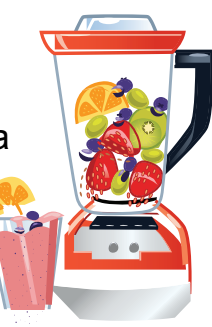

\section{3}

\section{coja un vaso de leche}

Una taza de leche sin o baja en grasa o leche de soya es una forma fácil de beber un refrigerio saludable.

\section{escoja granos integrales}

Ofrezca pan de harina integral, popcorn y productos

de avena integral que tengan alto contenido de fibra y bajo contenido de azúcares, grasas saturadas y sodio. Limite el consumo de productos con harina refinada como "snack bars," tortas y cereales azucarados.

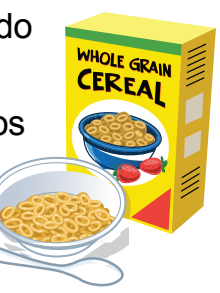

\section{- pique algo de proteína sin grasa}

Seleccione productos con proteína y sin grasa como embutidos bajos en sodio, nueces sin sal o huevos.

Envuelva un pedazo de manzana con tajadas de embutido de pavo o jamón bajo en sal. Guarde nueces peladas y sin sal en la despensa, también huevos hervidos en el refrigerador para que los niños los disfruten en cualquier momento.

\section{ojo con las porciones}

Los refrigerios no deben reemplazar a las comidas, para ello busque maneras de ayudar a sus niños a entender cuánto es suficiente. Guarde bolsas pequeñas para refrigerios y úselas para controlar las porciones que sirve.

\section{las frutas son rápidas y fáciles \\ Frescas, congeladas, secas o enlatadas las frutas son faciles para "coger y salir," son opciones que necesitan poca preparación. Ofresca frutas enteras y limite la cantidad de $100 \%$ jugo de frutas.

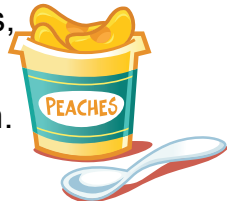

\section{considere conveniencia}

Una porción simple de yogur sin o

bajo en grasa o un pedazo de queso en envoltura individual puede ser justo la cantidad suficiente como para un refrigerio después de la escuela.

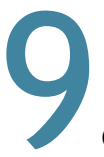

\section{reemplace los productos dulces} Mantenga los alimentos saludables a la mano para que los niños eviten las galletas, pasteles o dulces entre comidas. Adicione agua con gas a $1 / 2$ taza de $100 \%$ jugo de frutas en vez de servir soda.

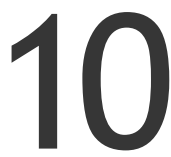

\section{prepare dulces hechos en casa}

Para dulces hechos en casa adicione frutas secas como albaricoque o pasas y reduzca la cantidad de azúcar. Ajuste las recetas que incluyen grasas como mantequilla o manteca y reemplace la mitad de la grasa con puré de manzana sin azúcar o puré de guindones (ciruelas secas).

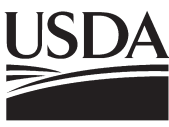

United States Department of Agriculture
Distribuido por UF/IFAS Extensión Visite www.ChooseMyPlate.gov para obtener más información.
DG TipSheet No. 24 Marzo 2013 Center for Nutrition Policy and Promotion EI USDA es un proveedor y empleador que ofrece igualdad de oportunidades para todos. 


\section{0 \\ consejos \\ Serie \\ de educación \\ en nutrición}

\section{alimentación saludable para un estilo de vida activa \\ 10 consejos para combinar buena alimentación y actividad física}

Para jovenes y adultos comprometidos a practicar deportes y mantener actividad física, la alimentación saludable es esencial para optimizar su rendimiento. La buena alimentación y la actividad física lo conducirán a un estilo de vida saludable.

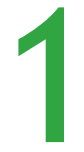

maximize alimentos nutritivos

Dé a su cuerpo los nutrientes que éste necesita escogiendo alimentos nutritivos; incluya cereales integrales, productos con proteína y bajos en grasas, frutas, vegetales y leche sin o baja en grasa. Coma menos alimentos ricos en grasas sólidas, azúcares adicionados y sodio (sal).

\section{revitalize con cereales}

La fuente rápida de energía de su cuerpo

proviene de alimentos como el pan, pasta, avena, otros cereales y tortillas. Asegúrese que por lo menos la mitad de los productos de grano que selecione sean integrales como pan, pasta o arroz integral.

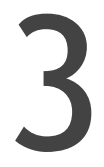

\section{enriquezca con proteína}

La proteína es esencial para desarrollar y mantener los músculos. Seleccione carne de res o cerdo baja en grasa, pollo o pavo sin pellejo. Obtenga proteína del pescado dos veces a la semana. Fuentes ricas en proteína también provienen de las plantas.

\section{consuma proteínas de origen vegetal}

¡La variedad es grandiosa! Seleccione legumbres (frejoles tipo riñon, pinto o negras; alverjitas; garbanzo y crema de garbanzo), productos de soya (tofu, tempeh, hamburguesas vegetales), nueces sin sal y semillas.

\section{5}

\section{diversifique las frutas y verduras}

Obtenga los nutrietes que su cuerpo necesita consumiendo variedad de colores en varias formas. Puré de bayas azules, rojas o negras; pimientos rojos o amarillos, verduras como la espinaca o acelga. Seleccione frutas frescas, deshidratadas, congeladas, enlatadas bajas en sodio o jugos $100 \%$ de frutas.
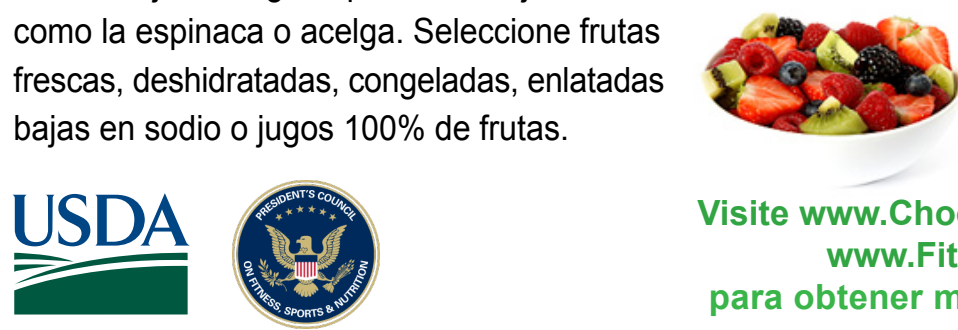

Visite www.ChooseMyPlate.gov y www.Fitness.gov para obtener más información. Distribuido por UF/IFAS Extensión

\section{no olvide los productos lácteos}

Alimentos como la leche sin o baja en grasa, queso, yogur y bebidas fortificadas de soya (leche de soya) ayudan a mantener los huesos sanos, tan necesarios para las actividades diarias.

\section{7 balancee las comidas}

Use MyPlate para recordar e incluir todos los grupos de alimentos en sus comidas diarias. Lea más en ChooseMyPlate.gov.

\section{( beba agua}

Manténgase hidratado bebiendo agua en vez de bebidas azucaradas. Guarde y reuse botellas de agua para tener siempre agua a la mano.

\section{conozca cuánto debe comer}

Obtenga información nutricional basada en su edad, sexo, altura, peso, actividad física actual y otros factores personales. Use SuperTracker para determinar sus necesidades calóricas, planee una dieta apropiada para usted y siga su progreso hasta llegar a su meta. Lea más en www.SuperTracker.usda.gov.

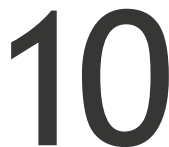

logre su meta

Obtenga reconocimiento presidencial por alcanzar sus metas de alimentación saludable y actividad física. Vaya a www.presidentschallenge.org para inscribirse al premio "Vida Activa Presidencial" (PALA por sus siglas en inglés).

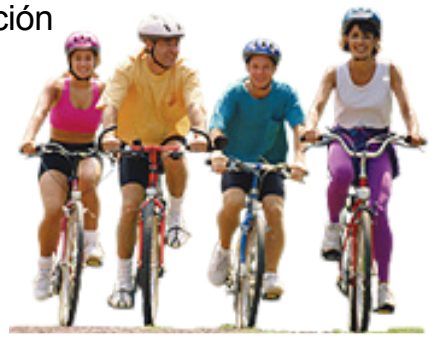




\section{0 \\ consejos \\ Serie \\ de educación \\ en nutrición

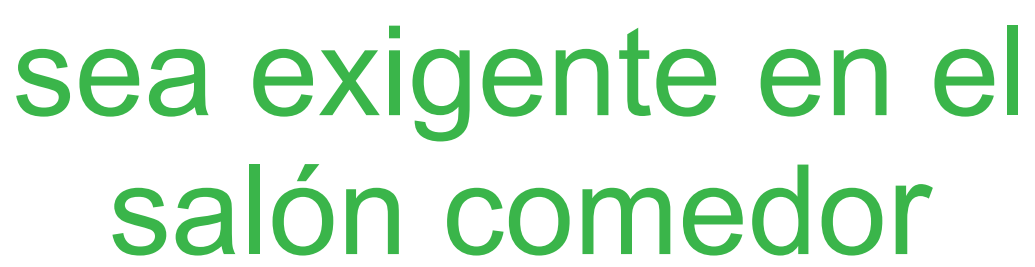

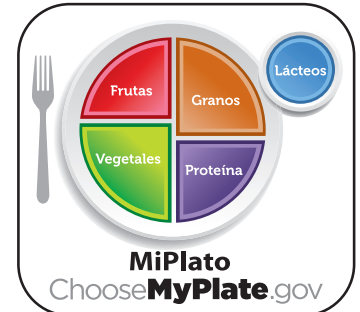

\section{0 tips para elegir alimentos saludables en el comedor}

Los comedores ofrecen muchas opciones saludables. Usted sólo necesita saber qué poner en su bandeja. Use estos consejos para planear lo que va a escoger y saber qué opciones son las mejores para usted.

\section{conozca lo que come}

Muchos comedores publican la información nutricional de sus menús. Revise los menús con anticipación, de tal manera que este listo para crear meriendas saludables y balanceadas en el momento que lo necesite. ¡Planear es el primer paso para tomar decisiones inteligentes a la hora de comer! Vaya a ChooseMyPlate.gov para encontrar información y herramientas como el SuperTracker para ayudarse a seleccionar alimentos en un tris.

\section{disfrute sus alimentos pero coma menos}

¡A todos les encanta los bufets, todo lo que pueda comer! Para evitar la urgencia de comer mucho, tome porciones pequeñas y use platos pequeños. Recuerde que usted puede servirse más si sigue con hambre.

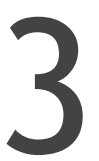

\section{¡haga que la mitad de los productos} de grano sean integrales!

Sea que este ordenando un sándwich o que se este sirviendo cereal en la manana, haga el cambio a productos integrales como pan o avena de $100 \%$ grano integral.

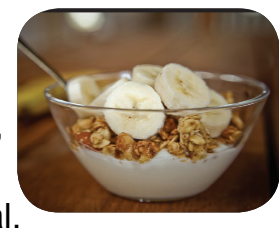

\section{reconsidere las bebidas que toma}

Los estadounidenses beben cerca de 400 calorías diarias. Considere la frecuencia con que toma bebidas azucaradas como gaseosas, refrescos, capuchinos, bebidas energéticas, jugos y té dulce. Beber agua en vez de bebidas azucaradas puede ayudarle a controlar sus calorías.

\section{- haga que la mitad de su plato sean frutas y vegetales}

Las frutas y vegetales pueden hacer sus comidas mas nutritivas, atractivas y sabrosas. Adicione éstos a las pastas, huevos, pizzas, sándwiches y sopas. Ponga espinaca en los burritos o piña a su pizza.

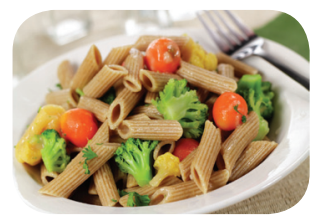

\section{¡prepárelo a su gusto!}

No piense que los platos ya preparados son mejores. ¡Cree sus comidas! Para la merienda puede preparar tortillas francesas con vegetales frescos de la barra de ensaladas. Como fuente de proteína use tofu en la estación de pastas para agregar algo de proteína sin grasa.

\section{disminuya las salsas}

Las salsas para ensalada, aderezos y aliños tienden a tener mucha grasa y sodio. Cuidado con los platos preparados con mucho aceite, mantequilla o servidos con condimentos pesados como la mayonesa. Usted no necesita servirse las salsas y condimentos al mismo tiempo, sírvase menos y a un costado del plato. Reduciendo los extras podrá mantener un peso saludable.

\section{este alerta en la barra de ensaldas}

La mayoría de los vegetales pueden pasar, pero limite el consumo de grasas y sodio como aceitunas, tocino, tallarines o pan frito y pasta o ensalada de papa, que estan preparados con mayonesa y aceite. Prefiera los aliños sin o bajos en aceite y servidos por separado.

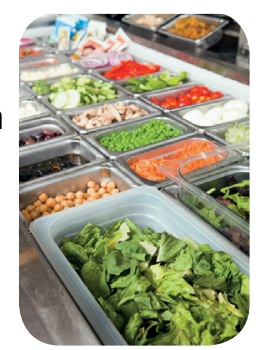

haga que el postre sea para ocasiones especiales

Guarde los postres para los viernes en la noche o alguna ocasión especial. Cuando realmente no lo pueda resistir, opte por algo más saludable como frutas o yogur con frutas.

\section{1 no se quede en el comedor por largas horas \\ Los comedores deben ser sólo para comer.} Aunque sea grandioso conversar con los amigos mientras come, evite quedarse por largos periodos de tiempo en el comedor para reducir la tentación de seguir comiendo.

DG Tipsheet No. 26

Distribuido por UF/IFAS Extensión Visite www.ChooseMyPlate.gov para obtener más información.
United States Agriculture

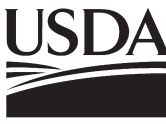

Marzo 2013
Center for Nutrition Policy and Promotion EI USDA es un proveedor y empleador que ofrece igualdad de oportunidades para todos. 


\section{0 \\ consejos \\ Serie \\ de educación \\ en nutrición
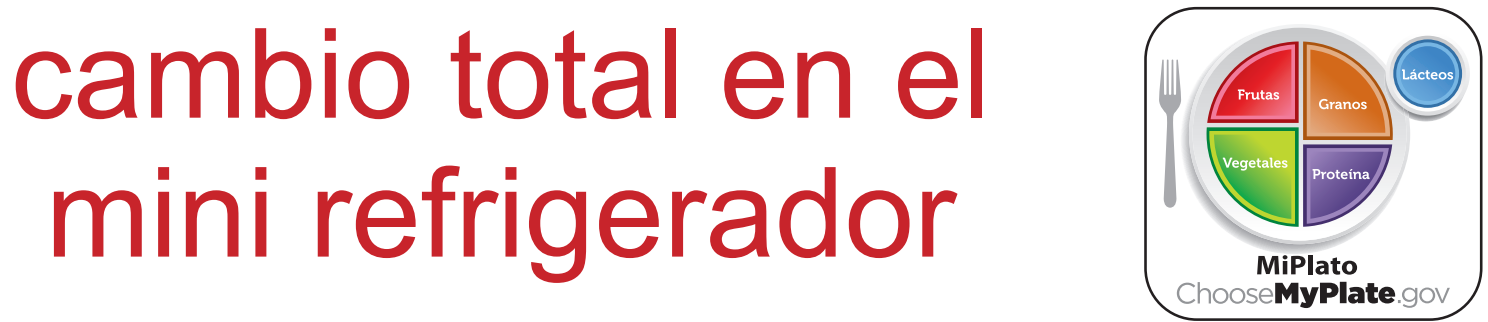 \\ 10 opciones saludables para mantener su mini refrigeradora*}

Almacene en su refrigeradora variedad de alimentos saludables. De esta manera tendrá varias opciones a la mano para el desayuno o un "snack."

\section{1}

\section{queso bajo en grasa}

Junte una tajada de queso con una rebanada de pan

integral para su refrigerio o lleve palitos de queso para un mordida rápida entre clases. ¡Los quesos bajos en grasa también se pueden usar para preparar tortillas españolas o quesadillas en el microondas de su dormitorio universitario!

\section{vegetales}

Es conveniente comprar productos lavados o cortados previamente para

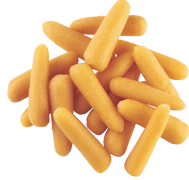
preparar "snacks" o comidas rápidas. Pruebe e incorpore a su dieta vegetales verdes, rojos, anaranjados y amarillos. Junte los vegetales con sus salsas favoritas, por ejemplo zanahorias con crema de garbanzos o apio con matequilla de maní o cacahuate. Adiciónelos a las tortillas españolas y quesadillas.

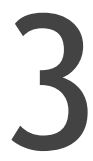

\section{frutas}

Recuerde que todas cuentan-frutas frescas, congeladas, secas y enlatadas. Fíjese en las variedades y en el contenido de azúcar o jarabes. Adicione una cuchara de pasas o albaricoques secos a su avena o yogur de la mañana; o incluya una manzana, fuente natural de energía, en su descanso durante la trasnochada de estudio.

\section{agua}

Mantenga agua en su refrigeradora. Invertir en una jarra con filtro es una forma de guardar agua en su dormitorio. Beber agua en vez de bebidas azucaradas es una alternativa saludable.

\section{nueces y mantequilla de nueces}

Estas durarán más si las guarda en el refrigerador. Pruebe con nueces, almendras, cacahuate o maní, avellanas, pistachos y nueces de la india. Los pedazos de manzana o tostaditas integrales son deliciosas con mantequilla de cahuate o de almendras.

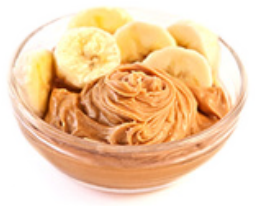

Visite www.ChooseMyPlate.gov para obtener más información. Distribuido por UF/IFAS Extensión

\section{huevos}

¿Huevos en su dormitorio universitario? Si tiene un refrigerador, íSí! Use un pocillo o taza para microondas para preparar huevos revueltos para el desayuno o un refrigerio rápido. Incorpore vegetales crudos y una cuchara de queso para adicionar sabor!

7 leche y yogur

Se puede incorporar leche sin o baja en grasa a la avena o cereales integrales, para un desayuno que llene y que sea nutritivo. Envases individuales de yogur o yogur griego bajo en grasa son convenientes y fáciles de llevar. Mezcle yogur con frutas y nueces para un desayuno energético o sírvalos con unos pedacitos de chocolate o canela para un postre saludable.

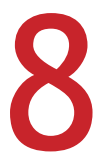

\section{crema de garbanzo}

¡La crema de garbanzo puede acompañar cualquier comida! Disfrute pedazos de pimiento rojo, zanahorias u otros vegetales crudos con esta crema. Unte pan pita integral con la crema de garbanzo y adicione tomate y pepino para un almuerzo saludable.

\section{salsa}

Una salsa fresca preparada con tomates, jalapeños, cilantro y cebollas es una manera divertida y jugosa para incorporar vegetales en su dieta. Sirva salsas bajas en sal con porciones pequeñas de tortillas o vegetales crudos.

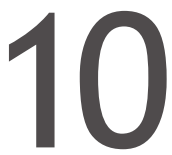
use la información nutricional de la etiqueta Use la información nutricional de la etiqueta para escoger bebidas y otros productos en el supermercado. La etiqueta contiene información sobre el contenido de azúcares, grasas y calorías. Leer la información nutricional de los empaques de los productos le ayudará a elegir mejor sus alimentos.

* Los refrigeradores deben mantenerse a una temperatura de $40^{\circ} \mathrm{F}$ o por debajo. Mantenga un termómetro en la refrigeradora para monitorear la temperatura.

DG TipSheet No. 27 Abril 2013 Center for Nutrition Policy and Promotion EI USDA es un proveedor y empleador que ofrece igualdad de oportunidades para todos 
10

consejos

Serie

de educación

en nutrición

\section{manténgase en forma en la universidad}

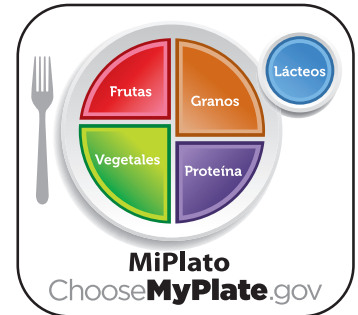

10 consejos para que los estudiantes universitarios se mantengan activos

Durante las clases y estudiando puede ser difícil mantenerse activo. Aún cuando ejercite por períodos de tiempo cortos, usted se sentirá mas energético y saludable. íLevántese y muévase!

1

vaya a clases caminando o en bicicleta

Si usted vive cerca del campo universitario, evite manejar o gastar dinero en transporte público, vaya a clases caminando o en bicicleta. Si maneja al campo universitario, cuadre el carro lejos del edificio para caminar más.

\section{use las gradas}

Los ascensores y las escaleras eléctricas son tentadoras, pero es mejor usar las gradas. ¡Este ejercicio es un buen hábito para empezar y al mismo tiempo le ayudará a fortalecer sus piernas!

\section{3}

\section{escoja un deporte}

Escoja un deporte que le interese y otro que lo mantenga activo en su tiempo libre. Si usted participó en un deporte en la secundaria como básquetbol o fútbol, usted puede seguir practicándolo en la universidad.

\section{4} afíliese al equipo universitario Esta es otra forma divertida de mantenerse activo. Muchas de las universidades ofrecen deportes clásicos como básquetbol o béisbol, otras instituciones ofrecen otras actividades como "frisbee" y boliche.

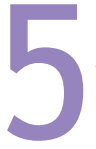
vaya al gimnasio

Visite el gimnasio de su universidad u otro centro recreacional. Salga a correr afuera, en una pista de carrera cubierta o practique a tirar canastas. Varíe la rutina para que no se aburra.

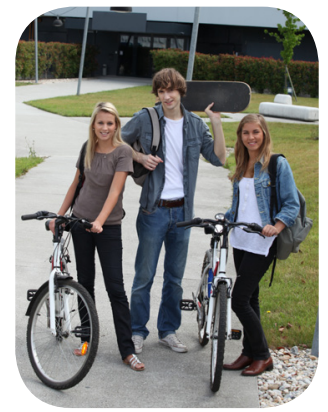

manténgase activo con los amigos ¡Invítelos a caminar o a montar bicicleta, este es un buen momento para compartir y divertirse!

\section{inscríbase en clases para mantenerse en forma}

La mayoría de universidades ofrecen clases económicas o gratis, busque el horario en internet y escoja una que pueda disfrutar, como yoga, baile, boxeo o aeróbicos para mantenerse en forma.

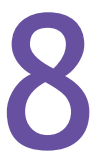
manténgase en forma y gane créditos Algunos cursos electivos como natación son una forma grandiosa de mantenerse activo mientras gana créditos. Estas clases no sólo son divertidas sino que ofrecen sesiones de entrenamiento una o dos veces a la semana. Inscríbase, anime a sus amigos y pruebe una clase nueva que le llame la atención.

\section{9} inscríbase para un viaje de aventura Muchas universidades ofrecen paseos de aventura como excursiones a pie o "water rafting" a precios con descuento. Chequee la página web de la oficina de recreación de su universidad para ver los eventos planeados para la temporada e inscribase para una clase activa.

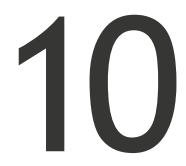

\section{balacee las calorías}

Lo que come es tan importante como lo activo que es. Tome

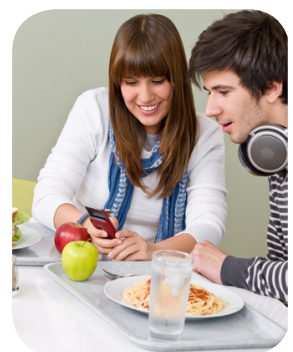
nota de lo que come y de la actividad física que realiza para mantener un peso saludable. Use la aplicación gratis en internet "SuperTracker" para tomar nota de sus metas y para mantenerse en forma: www.SuperTracker.usda.gov. (Disponible solamente en inglés.)

DG TipSheet No. 28 USDA

Distribuido por UF/IFAS Extensión Visite www.ChooseMyPlate.gov para obtener más información.
Center for Nutrition Policy and Promotion EI USDA es un proveedor y empleador que ofrece igualdad de oportunidades para todos. 


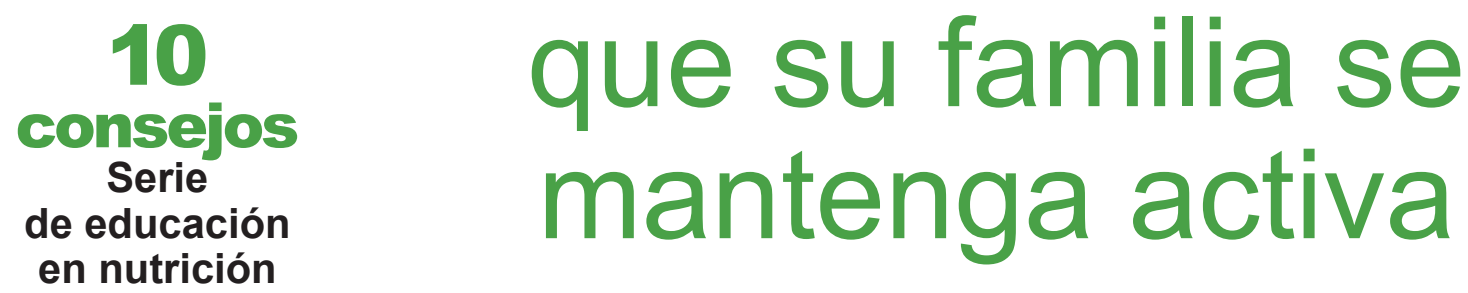

\section{0 consejos para que su familia sea más activa}

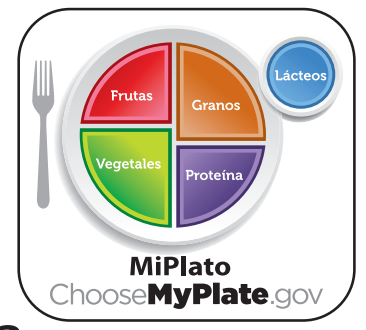

La actividad física es importante en niños y adultos de todas las edades. Mantener la familia activa puede beneficiar a todos. Los adultos necesitan $2 \frac{1}{2}$ horas de actividad física a la semana y los niños necesitan 60 minutos por día. Siga estos consejos para incrementar la actividad física de su familia.

\section{planee actividaes específicas}

Determine las horas en las que toda la familia esta disponible. Dedique algunas de éstas horas para la actividad física. Trate de hacer alguna actividad después de la cena o empieza el fin de semana con una caminata en la mañana del Sábado.

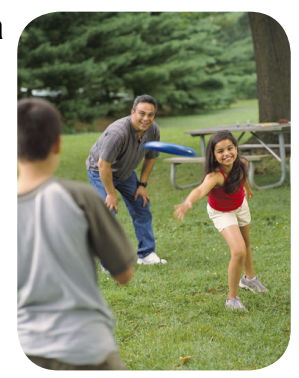

\section{planee con anticipación y tome nota} de sus logros

Escriba sus planes en el calendario familiar. Deje que los niños ayuden a planear las actividades. Permita que ellos marquen las actividades que ya realizaron.

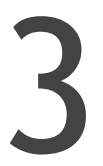
incluya el trabajo en la casa Deje que los niños participen en el trabajo del jardín y otras tareas de la casa. Ellos pueden ayudar rastrillando, deshierbando, plantando o aspirando.

\section{use lo que esta disponible}

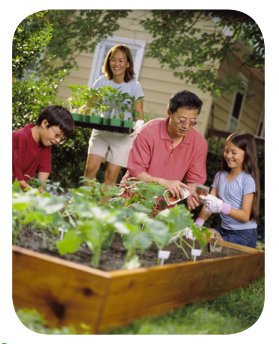

Planee actividades que no requieren herramientas

o espacios especiales. Ejemplos incluyen: caminar, trotar, saltar soga, jugar a las escondidas y bailar. Busque programas gratis o de bajo costo en los centros recreativos de su comunidad.

\section{desarrolle nuevas habilidades}

Suscriba a los niños en clases que los entretengan como: gimnasia, danza o tenis y ayúdelos a practicar. Esto ayudará a mantener las actividades divertidas, interesantes y desarrollarán nuevas habilidades. planee para todas las condiciones del tiempo

Escoga algunas actividades que no dependan de las condiciones del tiempo. Pruebe caminando en el centro comercial, natación en piscina cubierta o juegos activos de video. Disfrute actividades adicionales afuera cuando el tiempo lo permita.

\section{apague la televisión}

Establezca una regla de tal manera que nadie pueda ver TV, juegos de video o usar la computadora por más de 2 horas por día (excepto por las tareas de la escuela). En vez de un programa de televisión participe en un juego familiar activo, baile su música favorita o salga a caminar.

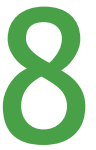

empiece poco a poco Empiece introduciendo una nueva actividad familiar y adicione más cuando vea que todos

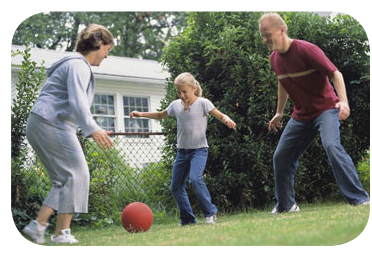
esten listos. Lleve al perro a largas caminatas, juegue con la pelota o vaya a clases de educación física.

\section{incluya otras familias}

Invite a otras familias a tus actividades. Esta es una manera para que sus niños compartan el tiempo con amigos mientras hacen actividad física. Planee fiestas con juegos activos como boliche, carrera de obstáculos, suscríbase en los programas familiares de YMCA o en un club recreacional.
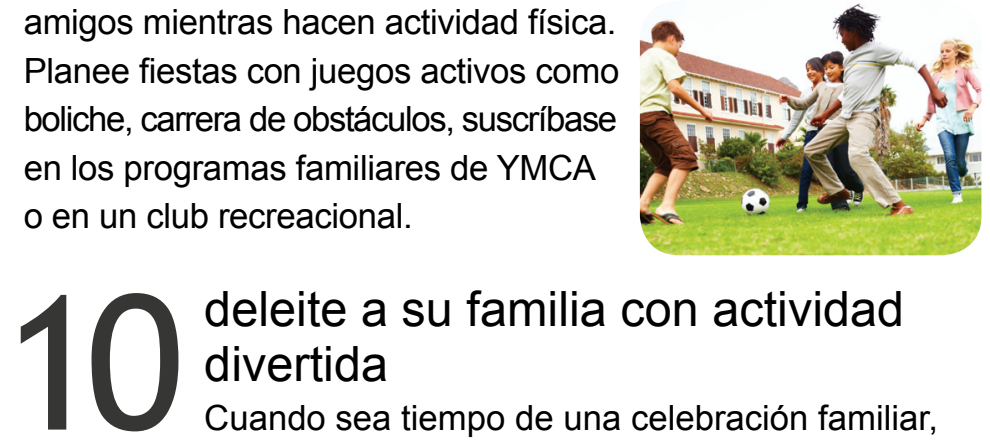

\section{deleite a su familia con actividad} divertida

Cuando sea tiempo de una celebración familiar, planee algo activo como premio. Planee un paseo al zoológico, al parque $o$ al lago, para deleite de todos.

DG TipSheet No. 29 Abril 2013 Center for Nutrition Policy and Promotion EI USDA es un proveedor y empleador que ofrece igualdad de oportunidades para todos.
Agriculture
Distribuido por UF/IFAS Extensión

Visite www.ChooseMyPlate.gov para obtener más información. 


\section{0 \\ consejos Serie \\ de educación en nutrición}

\section{adultos activos}

\section{0 consejos para que los adultos incluyan actividad física en su estilo de vida}

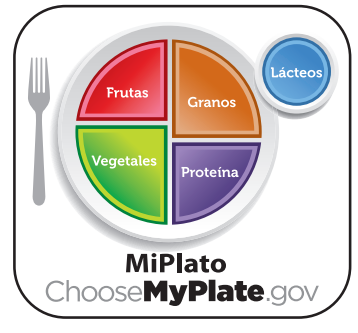

Mantenerse físicamente activo es importante para su salud. Los adultos que se mantienen físicamente activos tienen menos tendencia a adquirir enfermedades crónicas que los inactivos. La actividad física es cualquier forma de ejercicio o movimiento del cuerpo que usa energía. Gente de todas las edades, contexturas, tallas y habilidades se puede beneficiar con un estilo de vida activa.

empiece con actividades poco a poco, aumente la dificultad con el tiempo

Empiece lentamente si usted recién esta empezando a hacer activida física. Esto ayudará a prevenir lesiones. Después de algunas semanas incremente la frecuencia y el tiempo de su actividad.

\section{haga latir su corazón}

Para lograr los beneficios haga

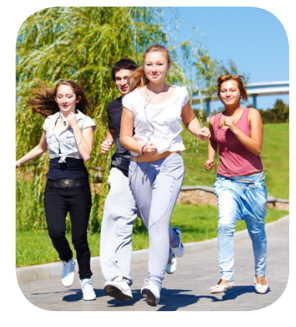

actividad física que requiera esfuerzo moderado por lo menos $2 \frac{1}{2}$ horas cada semana. Algunos ejemplos son: caminar a paso ligero, montar bicicleta, nadar y patinar. Distribuya sus actividades durante la semana, pero haga por lo menos 10 minutos cada vez.

\section{ejercicios de resistencia para mantener los músculos y huesos sanos} Haga ejercicios de resistencia dos veces por semana. Actividades de fortalecimiento incluyen: levantar pesas, abdominales, ejercitar con las bandas elásticas y trabajo intenso en el jardín.

\section{manténgase activo a través del día}

Cada actividad cuenta, incluso las más cortas se van acumulando, algo es mejor que nada. Suba las gradas en vez usar el elevador, camine por 10 minutos en su tiempo de descanso y cuadre el carro lejos de su trabajo para caminar.

\section{manténgase activo a su manera}

Combine actividades; hay muchas maneras de mantenerse activo. Estos incluyen: caminar, montar bicicleta, bailar, practicar artes marciales, jardinería y jugar con la pelota. Pruebe diferentes actividades para ver cual de ellas le gusta más y adicionar variedad. use el sistema de amigos

Las actividades con la familia o los amigos se disfrutan más que las actividades a solas. Júntese con un grupo para caminar, asista a clases de gimnasia o juegue con los niños afuera. Cree su grupo de apoyo; sus amigos le animarán

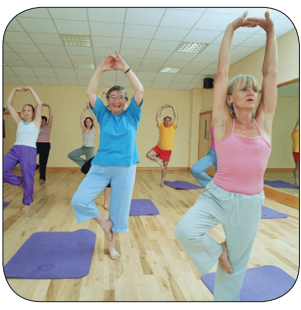
a mantenese activo.

\section{7} fije su meta y tome nota de su progreso Planee actividad física con anticipación y registre sus avances. Es una buena manera de lograr su meta. Registre sus actividades con el "Physical Activity Tracker" en el SuperTracker.* Use la función "My Journal” para anotar lo que le gusta hacer de tal manera que pueda construir un plan perfecto para usted.

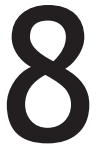

\section{incremente su tiempo activo}

Una vez que tenga una rutina de ejercicios, trate de incrementar su actividad física semanal. Cuanto más tiempo dedique a mantenerse activo, más beneficios de salud obtendrá

\section{9} incremente su esfuerzo Adicione actividades más intensas una vez que haya logrado actividad física moderada por un período considerable. Puede lograrlo empezando a correr en vez de caminar, nadar o montar bicicleta más

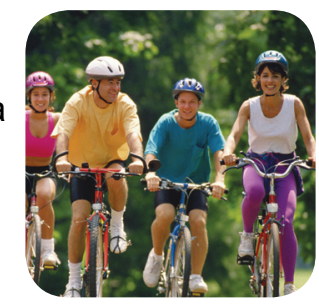
rápido, jugar fútbol y participar en danzas aeróbicas

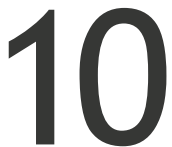
¡Diviértase!

La actividad física no debería ser una tarea. Le ayudará a sentirse y vivir mejor. Escoja actividades que disfrute y que se acomoden a su estilo de vida.

*Busque el "SuperTracker" en: https://www.SuperTracker.usda.gov.

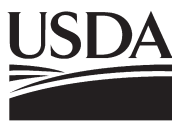

Agriculture
Distribuido por UF/IFAS Extensión Visite www.ChooseMyPlate.gov para obtener más información.
DG TipSheet No. 30 Abril 2013

Center for Nutrition Policy and Promotion EI USDA es un proveedor y empleador que ofrece igualdad de oportunidades para todos. 


\section{0 \\ consejos \\ Serie \\ de educación \\ disfrute comidas de \\ varias culturas}

en nutrición

\section{0 consejos para celebrar alimentos y costumbres más saludables}

Somos un país diverso y podemos abrazar las tradiciones culturales de las comidas que nos encantan, pero prepararlas de manera más saludable. Para ello debemos ser creativos y sustituir los alimentos e ingredientes menos saludables de nuestras recetas favoritas por otras opciones sabrosas y apetitosas, que igual nos recuerden nuestras preciadas costumbres alimenticias.

\section{cocine con otros}

Aprenda a cocinar distintos alimentos tradicionales o regionales de quienes usan recetas e ingredientes auténticos y explore formas de mejorar la nutrición de algunas de las recetas de su propia familia. Cocinar en casa le permite agregar variedad a las comidas. Si hace falta, adapte las recetas limitando las salsas de carne, cremas y otras salsas; agregue más vegetales; o prepárelas en el horno en vez de freírlas.

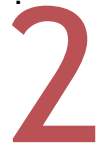

\section{combine culturas}

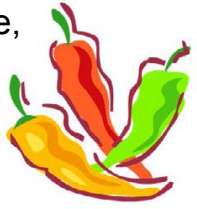

Muchos alimentos y bebidas populares en las Estados Unidos combinan la cocina de varias culturas. Celebre la diversidad de nuestro país e inspírese en platos que incluyan más frutas, vegetales, granos integrales, frijoles, mariscos, carnes magras y productos lácteos bajos en grasas.

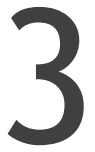

\section{agregue un toque de sabor}

Las combinaciones de hierbas y especias a menudo nos recuerdan platos de nuestros orígenes o comida étnica favorita. Agregue sabor a los alimentos con hierbas y especias, como chiles, ajo, jengibre, albahaca, orégano, curry o cilantro, que pueden reemplazar la sal y las grasas saturadas.

\section{4}

\section{use alimentos conocidos para crear} platos exóticos

Use alimentos que le resultan familiares y prepare nuevas recetas. Por ejemplo, agregue curry a los garbanzos, cilantro al arroz integral, o mango a sus ensaladas y batidos. Haga que la mitad de su plato sea frutas y vegetales.

encuentre la sal y el sodio, elija los contenidos bajos

Todos los alimentos empaquetados indican la cantidad de sodio que contienen. Use salsa de soja "baja en sodio," o caldos o frijoles enlatados que indiquen "sin sal agregada." Controle la información nutricional y use productos bajos en sodio o libres de él.

\section{piense en las bebidas}

Muchas culturas ofrecen bebidas sabrosas, como jugos de frutas, bebidas alcoholicas, cafés cargados y tés dulces. Considere usar frutas congeladas para crear batidos deliciosos, o agregar especias, productos lácteos bajos en grasas y cantidades de azúcar pequeñas cuando prepare bebidas. Cuando compre bebidas preparadas, elija aquellas con menos azúcares y grasas. Para limitar las calorías, beba agua $\mathrm{u}$ otras bebidas no endulzadas en vez de bebidas azucaradas.

\section{7} deléitese en las reuniones culturales Celebre las tradiciones, especialmente aquellas que lo ayudan a mantenerse físicamente activo. Diviértase con los bailes, deportes y juegos tradicionales que hagan mover. Equilibre su alimentación con actividad física regular.

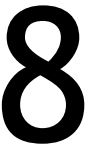
enseñe a los niños qué es importante Los niños aprenden a cocinar de sus mayores. Muéstreles como se preparan los alimentos y platos de distintas tradiciones. Deje que prueben los alimentos que preparan y comparta con ellos historias y costumbres relacionadas de su propia herencia, o expóngalos a otras culturas, pero busque formas de limitar los alimentos e ingredientes con muchas calorías.

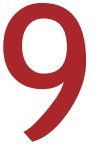

sea inteligente cuando coma fuera

Comer fuera pone a su alcance nuevos

platos tentadores, que facilitan los excesos. Elija platos con menos calorías, como aquellos fritos en poco aceite, brochetas (kebab), o pastas de harina integral con salsa de tomate. Divida los platos o pida un envase antes de empezar la comida para separar una parte de lo que le sirvan y llevársela a casa.

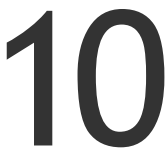

recuerde, las comidas de todo tipo entran en MiPlato

MiPlato ha sido diseñado para que los estadounidenses recuerden alimentarse saludablemente con comidas de los grupos de alimentos. El sitio web MiPlato brinda información práctica, consejos, herramientas y recetas que lo ayudarán a llevar una dieta más saludable. Visite www.ChooseMyPlate.gov.
Distribuido por UF/IFAS Extensión

Visite www.ChooseMyPlate.gov para obtener más información. 